\title{
Making Better Decisions: Utilizing Qualitative Signed Digraphs Modeling To Enhance Aquaculture Production Technology Selection
}

Authors

Andrew S. King* - Institute for Marine and Antarctic Studies, University of Tasmania, Hobart, 7000, Australia. Tel.: +44 7912065577 E-mail: andrew.king@utas.edu.au Nicholas G. Elliott - CSIRO, Castray Esplanade, Hobart, Tasmania, Australia.

Catriona K. Macleod - Institute for Marine and Antarctic Studies, University of Tasmania, Hobart, Australia.

Mark A. James - Scottish Oceans Institute, School of Biology, University of St Andrews, East Sands, St Andrews, Fife, KY16 8LB, United Kingdom

Jeffery M. Dambacher - CSIRO, Castray Esplanade, Hobart, Tasmania, Australia. ${ }^{*}$ Corresponding author 


\title{
Making Better Decisions: Utilizing Qualitative Signed Digraphs Modeling To Enhance Aquaculture Production Technology Selection
}

\begin{abstract}
Understanding causal relationships within complex business environments represents an essential component in a decision-maker's toolset when evaluating alternative aquaculture production technologies. This article assesses the utility of employing signed digraph qualitative modeling to support technology selection decision-making through evaluating the adoption of three alternative production expansion strategies (offshore production, IMTA, or land-based RAS) by the Atlantic salmon industry. Results underlined the benefits of strategically understanding the dynamics of demand growth, emphasized the requirement to address societal concerns early; and indicated that levels of ambiguity are lowest with expansion offshore and highest with land-based RAS growout. The research suggests that signed digraph modeling can provide an objective perspective on the levels of uncertainty and causal linkages within a business environment when exploring aquaculture adoption technology scenarios.
\end{abstract}




\section{Making Better Decisions: Utilizing Qualitative Signed Digraphs Modeling To Enhance Aquaculture Production Technology Selection}

\section{Introduction}

The efficacy of adopting emerging alternative production technologies and strategies to expand the aquaculture industry is subject to a multiplicity of interrelated impacts. In particular, as production within a region matures the business environment becomes increasingly complex, and the challenges associated with achieving and maintaining a 'social-license to operate' rise (Bostock et al., 2010; Arnot, 2014). (Osmundsen et al., 2017) To better assess, understand and manage within this multifaceted environment the industry would benefit a decision-support approach that can capture, relate and adjust the many conflicting elements associated with societal concerns, technical production requirements and market economics.

Traditionally modeling efforts to support development and expansion in the global aquaculture industry have relied upon relatively simple comparative modeling using spreadsheets (Nunoo et al., 2014; Boulet et al., 2010). These have been accompanied by economic projections of supply and demand (Kobayashi et al., 2015; Murray and McDonald, 2010; Liu and Sumaila, 2007); the application of geographical information system analysis to identify and scope development potential (Hossain et al., 2009; Benetti et al., 2010); the numerical simulation of site discharge loadings and site biomass modeling (Henderson et al., 2001; Brigolin et al., 2010; Murray, 2001); and the formulation of top-level strategic plans (Henderson et al., 2001; Brigolin et al., 2010; Murray, 2001; Fisheries and Oceans Canada, 2010; NT 
Department of Resources - Fisheries Group, 2011). These approaches, while useful, can only represent isolated snapshots of the system and don't reflect the dynamic interactions or feedbacks operating within the business environment, nor do they take any account of the broader processes / interactions that might occur outside of the production environment. Increasingly there has been recognition of the wish for decision-support techniques and understanding that can better reflect the responses and links between social, economic and technical factors in relation to aquaculture systems (Waite et al., 2014; Klinger and Naylor, 2012; Muir et al., 1999), and the regulatory responses from public agencies (Osmundsen et al., 2017).

Qualitative signed digraph (sign directed graph) models are one way that a holistic overview of a process or industry can be developed (Levins, 1966). These models are focused on defining the causal relationships (feedbacks and interactions) between variables, and increasing the understanding of current and future dynamics, thereby providing the ability to predict the direction by which a system might change as a result of any perturbation or intervention. Such models can incorporate different components (i.e. governing bodies and markets) and processes (i.e. local customs) that are important in defining the outcome but have traditionally been difficult to incorporate. The sign digraphs are relatively easy to construct and can be used to identify key relationships and processes, highlight data-gaps, distinguish change thresholds, assess the systems stability (i.e. the propensity to return to equilibrium) (Levins., 1974; Dambacher. et al., 2002), and to formulate management strategies aimed at understanding and influencing the 'tipping points' of the system (Bodini et al., 2000). 
The technique has been extensively applied in natural resource management, including fisheries (Metcalf et al., 2009, Dambacher et al., 2009, Ortiz and Levins, 2011, Li and Moyle, 1981) and has been used to help address a range of societal challenges (Loiselle et al., 2002). Signed digraph modeling can also be applied to economic (Samuelson, 1983; Quirk and Ruppert, 1965) and investment decisions (Maskin, 2008; Benaroch and Dhar, 1995). However, this qualitative modeling technique does not appear to have been applied in aquaculture decision-making, nor have the triumvirate elements of business development (societal, economic and technological) been combined in such modeling.

The purpose of this study is to address this challenge by undertaking an assessment of the applicability of qualitative signed digraph modeling to support aquaculture decision-making. Specifically, through evaluating the selection of alternative growout production technologies by the Atlantic salmon aquaculture industry. An industry where rapid technological change has driven productivity growth and improved management (Asche, 2008; Kumar et al., 2016).

\section{Method}

\subsection{Signed Digraphs Qualitative Modeling}

Qualitative signed digraph modeling uses sign-directed graphs to portray the structure of the system to be modeled. Through defining the core variables and their direct relationships the links from one variable to another are depicted in signdirected graphs by lines ending in either: an arrow $(\rightarrow)$ to represent a positive direct effect; a filled circle (-•) for a negative direct effect (Puccia. and Levins, 1985; Dambacher. et al., 2002); or a square annotated with a +/- for an effect that can be 
either positive or negative depending on certain conditions. Self-effects are shown as links that start and return to the same source variable, and reflect influences from factors outside of the system, or density dependent growth (for a biological system).

To illustrate through a stylized example (Figure 1). The process of spatial regulation for (sea-pen ${ }^{1}$ ) aquaculture can be broadly represented by two variables Aquaculture Production (X1) and Spatial Constraints (X2), (Figure 1), with the links and interactions between these variables denoted in matrix format (Dambacher. et al., 2002).

\section{Insert Figure 1 here}

In this 'Community' matrix, each $a_{i j}$ element represents the direct effect of variable i on variable j (Figure 1). In the example shown, spatial constraints (row 2) can be seen to increase (1) from a perturbation (a sustained external pressure) to aquaculture production (column 1), while aquaculture production (row 1) is negatively impacted $(-1)$ by an increase in the spatial constraints (column 2). As production within a region $\left(\mathrm{X}_{1}\right)$ increases, the availability of suitable seawater space reduces and thus spatial constraints $\left(X_{2}\right)$ rise $\left(X_{1} \rightarrow X_{2}\right)$. Correspondingly should spatial constraints increase by say the designation of a marine protected area, this will stimulate a negative direct effect on production $\left(\mathrm{X}_{2}-\bullet \mathrm{X}_{1}\right)$, thereby stabilizing aquaculture development within a region to an 'acceptable' level.

To reflect both direct and indirect interactions between variables the Adjoint matrix (a conjugate transpose of the Community matrix) is derived (Dambacher. et al., 2003). The direction of change (increase or decrease) of all the systems variables after a sustained change (perturbation) is given by the signs of the Adjoint matrix 
coefficients (Figure 2). When negative, a feedback cycle returns the opposite effect to an initial change to a variable and acts to maintain equilibrium, whilst positive feedback keeps displacing a variable away from its original value, increasing a system's sensitivity to a sustained change (a perturbation).

\section{Insert Figure 2 here}

The net number of effects detailed in the Adjoint matrix can also be used to assess the relative magnitude of a predicted response, and the feedbacks and dynamics of the model (the mix of positive and negative cycles at each level) can be examined to determine how the system responds to perturbations (sustained changes). This can help decision-makers better understand the complexities of the system behavior, providing insights into questions such as: what is the impact or direction of change for any component variable given a specific perturbation; and, does the perturbation(s) affect all system variables, or only a few?

Predicting the overall effect of a change (perturbation) to system variables requires the total number of positive and negative effects (both direct and indirect) to be accounted for (Dambacher. et al., 2002). If all effects are of the same sign then there will be absolute sign determinacy in a model's predictions (i.e. the nature of the change in response to perturbation will be fixed). If however, there are both positive and negative effects involved, then the sign of the response is ambiguous and more information is useful to predict the outcome. Where the relative strengths of the interactions involved in a response prediction are known, then the sign of a response can be clearly assigned. Where this knowledge is lacking a probabilistic interpretation of sign determinacy can be gained from analyzing the relative balance 
of positive and negative effects transmitted to a response variable (Dambacher. et al., 2002). Here the ratio of net to total number of effects is used to define a prediction weight, which can then be used to assess the likelihood for sign determinacy in model predictions. For instance, a response prediction based on three negative effects and one positive effect can be said to have a net of two negative effects, from a total of four, giving a prediction weight of $2 / 4=0.5$. Previous research has suggested that a cut-off of $85 \%$ probability should be employed to distinguish response predictions with a high likelihood of sign determinacy from those that are ambiguous (Dambacher et al., 2003, Hosack et al., 2008).

\subsection{Model Development}

The first stage in developing the qualitative models was to i) capture the key factors in the macro and micro business environments, ii) define the trends and drivers that operate on the Atlantic salmon industry, and iii) understand the alternative production technologies and strategies. One hundred and twenty-nine interviews were conducted internationally (Australia, Canada, Denmark, Ireland, Norway, Scotland, USA) with aquaculture farmers, environmental non-governmental organisations, equipment manufacturers, government policy and regulatory bodies, retailers, and research organisations during 2012.

\section{Insert Table 1 here}

Using mind-mapping software (SimpleMind, version 1.8.3, from ModelMaker Tools BV) these factors were broadly categorized against a PESTEL (political, economic, social, technical, environmental and legal) framework, and production technology 
drivers identified. From the mind-map, 14 key variables (processes, economic drivers, and societal, political and policy considerations) influencing aquaculture production and development within a region were formulated and defined, Table 2. (Note: These variable names and numbers are used consistently within all models, and are identified in the paper's text by inclusion within parentheses).

\section{Insert Table 2 here}

A signed digraph model (Figure 3) was then created, and an associated Community matrix representation (Appendix A) generated using PowerPlay analysis software (Microsys, Generation 5) to reflect the core drivers and regulatory structures associated with salmon aquaculture production, and their associated direct interactions (i.e. a change to Variable A directly results in a change to Variable B), Table 3. This baseline signed digraph model effectively representing the dominant production methodology for the growout phase of Atlantic salmon farming - inshore sea-pen culture. The convention of illustrating changes from a positive impact to a variable being adopted throughout the study (Dambacher. et al., 2003).

Insert Figure 3 here

Insert Table 3 here

\subsection{Technology Adoption Perturbations}

To examine the dynamics of the salmon industry and how this might affect adoption of alternative grow-out production technology expansion strategies 9 perturbation scenarios were then applied against the baseline (inshore sea-pens) model, Table 4 details. These scenarios explore adoption of three alternative production expansion options (King et al., 2016): 
i) moving sea-pen production offshore into higher energy waters;

ii) adopting natural bioremediation principals through Integrated Multitrophic Aquaculture (IMTA); and

iii) developing land-based recirculating aquaculture systems (RAS).

Each scenario modeled consisted of a simultaneous perturbation, positive or negative, between three and six system variables (Table 4). This was achieved by adding a specific perturbation variable in the Community matrix representation of the system (Dambacher. et al., 2002) - Appendix B illustrates.

Response predictions to the perturbations were then calculated using the methods of Dambacher and Hosack (Dambacher et al., 2003; Hosack et al., 2008). Mathematical algebra software (Maple 13, from Cybernet Systems Ltd, (Dambacher et al., 2005) was used to run the analysis code (Versions 3 and Beta 4).

\section{Insert Table 4 here}

Perturbation scenarios I to III (Table 4) represent expansion offshore by the industry, using sea-pen technology, into a remote location or high-energy environment (Figure 4). Adoption of this strategy would address many of the social challenges (5) associated with further development into inshore waters (TheFishSite Newsletter., 2012c). In addition, the cost of production will be reduced through capital cost economies of scale (10), and biological production efficiency (9) improvements associated with better water quality (Kirchhoff et al., 2011; Benetti et al., 2010). Any impact on spatial constraints (4) and environmental loadings (13) with offshore farms will be dependent on their location. The impact of location on: environmental loading is reflected through reduced loading (I) and no impact (II and 
III) scenarios; and on spatial constraints (4) through scenarios I and II (reduced) and a neutral impact by 2030 (scenario III).

\section{Insert Figure 4 here}

Adoption of natural bioremediation principles by the salmon industry through IMTA (Figure 5) is characterized by perturbation scenarios IV and V (Table 4). Adoption of this expansion strategy would reduce marine environmental loadings (13) (Hughes and Kelly, 2011) and strengthen a company's sustainability credentials (14) (Ridler et al., 2007; Shuve et al., 2009). However, spatial constraints (4) may increase, whilst economic impacts (9 and 10) would depend upon the personnel regime (i.e. whether it is possible to utilize existing manpower, or to recruit new personnel) and the requirement for incremental capital. Therefore, the two IMTA perturbations modeled reflect quite different economic outcomes; one with an impact on cost of production (perturbation scenario IV), and one without an impact (V), (Table 4).

\section{Insert Figure 5 here}

The third expansion option, establishing a land-based RAS growout system (Figure 6), is represented by four perturbation scenarios (VI to IX), Table 4. Adoption of RAS technology by the industry would reduce marine spatial constraints (4), enhance sustainability credentials (14), and increase production efficiency (9). However, higher capital costs (10) will be incurred (King et al., 2016). The impact on environmental loading (13) will depend on waste discharge and processing, and therefore reduced loadings have been assumed for Scenario VI (Table 4). The greatest uncertainty with this option is associated with how society would respond; 
increasing societal concerns are reflected in perturbation scenarios VI and VII, neutral impact in scenario VIII, and reducing concerns in scenario IX.

\section{Insert Figure 6 here}

\section{Results}

\subsection{Salmon Aquaculture's System Dynamics}

Analysis of the signed digraph model reveals twenty-three discrete interaction sequences or loops (Table 5), which drive and regulate salmon aquaculture. Each loop forms a cyclical conjunct with either two (7 cases), three (2), four (3), five (5), six (4), or seven (2) links. All of these feedback loops are negative, except for three cycles (of lengths five, six and seven) that are positive, thus in general leading to a mutual reinforcement of a variable. The three positive feedback loops account for only $2 \%(992)$ of the total $(58,272)$ number of cycles, and reflect the system's predominantly unidirectional nature.

\section{Insert Table 5 here. Landscape format recommended}

These feedback cycles together with the interactions between component variables, describe the behavior and dynamics of the entire system. Categories of cycles can explain the core processes of aquaculture production (Table 5). Aquaculture production is subject to spatial, environmental and societal regulation (Figure 7). Spatial regulation $(1 \rightarrow 4-\bullet 1)$ is defined by increased production reducing the availability of (in-shore) marine water space for further expansion. While environmental regulation $(1 \rightarrow 13 \rightarrow 11-\bullet 1)$, has an additional process step with heightened environmental loadings imparting a regulatory response. Finally societal regulation results from social license (societal) concerns reducing political support 
for aquaculture, which in turn results in tighter regulatory requirements and impacts on production $(5-\bullet 12-\bullet 11-\bullet 1 \rightarrow 5)$.

\section{Insert Figure 7 here}

Societal feedback cycles generally address challenges associated with food security or environmental concerns, through enabling the substitution of international supply (3), or through production regulation (11), (Table 5). To demonstrate, the loop $(8 \rightarrow 5-\bullet 12 \rightarrow 11 \rightarrow 4-\bullet 1 \rightarrow 6-\bullet 8-\bullet 5)$ shown in Figure 3 shows that as demand (8) increases social license concerns (5) rise, this results in a reduction in political support (12) and a hardening of the regulatory authority's attitude (11) such that the space (4) for expansion is constrained. This leads to a lower equilibrium level of aquaculture production (1), increased price (6) through the supply and demand (8) mechanism and consequently a resultant reduction in societal concern.

Interestingly the model results also identify a somewhat Machiavellian scenario from the perspective of social license. A positive self-enhancing societalpolitical feedback cycle which floods the market with imports, leads to falling price, which increases demand and as a consequence social license concerns rise, which then suppresses political support for the local domestic industry and as a consequence increases the likelihood of imports $(3-\bullet 6 \rightarrow 8 \rightarrow 5-\bullet 12 \rightarrow 3)$. However, this feedback cycle does assume that consumers are oblivious to the provenance of the salmon they consume ${ }^{1}$.

\footnotetext{
${ }^{1}$ This will be market dependent. For example, Japanese consumers show a preference for wild and eco labeled fish (Uchida et al., 2014), whilst in Germany an ASC eco label can lead consumers to have the same preference farmed salmon as for wild MSC labeled salmon (Bronnmann and Asche, 2017).
} 


\subsection{Technology Perturbation Scenarios}

The modeling results show that $68 \%$ of the predictions (73 of the 108), from the nine technology perturbation scenarios had a moderate to high probability of sign determinacy. Social License Challenge (5) had the highest incidence (8 of 9) of low probability of sign determinacy, while Production Efficiency (9) and Financial Cost (10) had greatest incidence of high probability (>85\%) predictions, (Table 6).

Whilst the perturbation scenarios within each of the individual expansion strategies don't differ notably in sign, except in the level of ambiguity, a significant difference can be observed between the three expansion options, offshore, IMTA and RAS. Ambiguity increased when moving from the offshore-based scenario to IMTA, and again on moving to land based recirculation aquaculture, the latter having the highest level of uncertainty (Table 6).

Furthermore, the analysis highlights that for all the expansion options the greatest level of ambiguity was associated with societal concerns, i.e., Social License Challenge (5), (row 3 in Table 6). Reinforcing that social license is the key uncertainty, and potentially the area that benefits from most attention in terms of understanding the dynamics of what is going on.

\section{Insert Table 6 here}

Broad comparisons can be made between the alternative production expansion technologies. The complied perturbation responses from the scenarios (Figure 8) indicated that: 
1. the greatest positive impact on aquaculture production could potentially be achieved through expanding offshore, (point A highlights):

2. expansion offshore has the greatest relative impact on reducing the cost of production (point $B)$; and

3. societal concerns are likely to be the highest when land-based RAS is adopted (point C).

Insert Figure 8 here

Furthermore, since the perturbations (increase or decrease) in production efficiency (9) and financial cost (10) derive the same strength, +/- 30 (point D), further quantification is required to understand the comparative intensities of these links.

\section{Discussion}

Overall the study demonstrated that signed digraph models can provide a very useful tool for both developing a causal understanding of the dynamics that drive the salmon aquaculture industry and exploring scenarios of change, and that this in turn can inform the future proofing of aquaculture production technology selection. Signed digraph models enable the complex interactions within the business environment to be both quickly and simply defined, and furthermore these interactions can be easily developed and modified to reflect regional or societal differences. It is however, important to be aware that that the signed digraph models derived were dependent upon the interviewed experts responses, and to appreciate the limitations of the modeling and that interpretation of signed digraph results can be enhanced through adopting complementary decision-making techniques. 


\subsection{Change Dynamics}

The system dynamics represented through the modeling have implications for aquaculture decision-making, identifying in particular the usefulness of understanding demand growth drivers and societal issues. Critically, this analysis highlighted that the aquaculture industry should identify societal challenges, and take action to maintain demand and avoid potential boom and bust impacts.

Interaction between demand and the societal challenges associated with aquaculture production (link $8 \rightarrow 5$ in the models) can evolve concurrently from the causal drivers responsible for growth in demand. The development of this direct interaction (link) is subject to many external factors. For instance, some societal concerns can be transient, e.g. anxieties associated with health or animal welfare resulting from media campaigns, whilst others are structural in nature, e.g. population demographics. In particular, structural sources of increases in demand for salmon within a defined region, assuming no imports, may be caused by growth in: i) the customer base; a rising population and new market sectors and ii) per capita consumption; driven by health and wellbeing factors, population age demographics, ethnicity or the overall affluence of society.

Potential interactions between demand and social license challenges will be shaped by these structural causal drivers (Figure 9). To illustrate this point: where increased public awareness of the health benefits of eating salmon results in increased per capita consumption, (thereby assuaging social concerns), no link will develop (Sub-model A, Figure 9). Should a progressively affluent consumer base drive demand, with society becoming increasingly concerned about the impact of aquaculture production, a positive link between demand (Dem) and social license 
challenge (SLC) would develop (Sub-model B). In contrast a negative link may arise where social license challenges demand $(5-\bullet 8)$ in response to growth in demand driven by an aging population (Sub-model C). This affluent and retired population, with a desire for a coastal lifestyle and amenity, raises concerns with aquaculture production to the extent that demand is impacted.

\section{Insert Figure 9 here}

The modeling suggests that any impact on demand due to societal concerns is conditional on the relative strength of the pathways between these two variables and the level of moderation afforded by sustainability credentials. The comparative strengths of these interactions, and therefore potential emergence of any social license challenges, can differ significantly between countries, and within national regions. For example, in Australia should a negative link (5-•8) develop due to NIMBY (not in my back-yard) concerns in elements of the local consumer base, the strength of this link will be weak in comparison to increases in demand from the core Australian mainland market. In contrast in Canada, public concerns and national debates over environmental and economic impacts of the industries (TheFishSite Newsletter., 2012a; TheFishSite Newsletter., 2012b) have led to a strengthening of the negative links $(5-\bullet 12)$ and $(5-\bullet 8)$. This has been amplified by a government inquiry into sea-pen aquaculture (Cohen, 2012) (a perturbation to political support and production regulations) and the injection of ENGO finance (a perturbation into the cost of production sub-variable) to pursue a vanguard land-based RAS project (Kuterra, 2014). Furthermore, the results from the signed digraph modeling will accordingly depend on the parameterization adopted between social license and 
demand. For instance, Sha et al. (2015) show a strong impact of negative media coverage on US salmon imports, whilst Liu et al., (2016) found little impact of media coverage on salmon demand in Norway. It is also a relative issue, since as demand for salmon has been increasing rapidly globally as well as in main regions (Brækkan et al., 2014), the impact of social concerns may well result from the pace of the demand growth rather than the sign of this interrelationship.

\subsection{Technology Selection}

The qualitative method used in this study does not specify which technology route expansion development will or should take, as all the predictions have a degree of ambiguity in them. However, the finding that the modeled dynamics for expansion offshore into higher energy waters are the most predictable (i.e. have the least level of ambiguities) supports the industry's pursuit of this strategy (Hanson, 2014; Ryan et al., 2007; Jervell, 2014). Moreover, as such expansion is unlikely to impact on the current level of spatial constraints associated with inshore waters, the perturbation scenario III (neutral impact on spatial constraints) is probably the most representative for the industry overall.

Signed digraph modeling does however identify what variables to observe, and potentially gives an indication (or confirmation) of why a county or region might head down one route rather than another. Predictions can help distinguish the most suitable production expansion technology and the degree of alignment with a corporate or industry strategy. The dynamics of the models highlight the comparative strengths of the options. Namely expansion offshore would be primarily encouraged by spatial, environmental and social license drivers as well as the desire to enhance production efficiency; IMTA adoption is encouraged by 
environmental and certification drivers but discouraged by spatial challenges; and acceptance of land-based RAS is fostered by lower cost of production, an absence of societal concerns associated with animal welfare or the land footprint, and societal recognition of the technology's environmental credentials.

The observation from the digraph modeling that the greatest level of ambiguity is associated with societal concerns reinforces the critical role that this can have on technology selection. Furthermore, it underlines the industry's proactive marketing of the sustainability credentials of their inshore sea-pen farming. This marketing acts as a perturbation to stimulate demand, and also to help mitigate the risk of emerging societal concerns by reinforcing the sustainability credentials of the production technology.

\subsection{Decision-Making}

Adopting the rigor of creating (or refining) a signed digraph model, provides the opportunity for aquaculture decision-makers to explicitly evaluate underlying assumptions and decisions, and to test the fallacy or not, of a perceived process. By highlighting key parameters and interactions, the modeling indicates where the uncertainties are, and the levels of ambiguity. Indeed, employing sign digraphs in this way could be viewed in the context of 'traffic-light' decision-making; highlighting the ambiguities and structural uncertainties that should be resolved before investing. This type of modeling is particularly suited to the conceptual design stage of an aquaculture venture. Loiselle et al. (2002) suggested that qualitative modeling is particularly useful to guide decision-makers when looking at new and developing areas. Strategically, this approach allows exploration of ways to achieve an 
objective, identifies any points of intervention, and points to opportunities for the strategic 'hijacking' of positive feedback or the material conversion of negative loops. It also enables an enterprise to rapidly explore the potential effects of highseverity structural changes (perturbations) such as spikes in feed costs, unexpected price drops or major technological breakthroughs.

Qualitative signed digraph modeling can be used very effectively to develop local and regional models, when there are marked differences in the business environment. For example, the impact on demand of negative perceptions (the Machiavellian argument highlighted in Section 3.1) assumes some domestic production but with import dependence. This would not be the case for the major produces, Norway and Chile, and nor for the main consumers such as France where there is no production. Additionally changes to the system processes over time can be readily modeled, thereby helping to avoid short-term tactical 'planning blindness' (Christensen, 1997, FAO, 1996). This feature is especially valuable in an industry like aquaculture that necessitates significant upfront investments before economic returns can be delivered and where the industry's business environment is prone to emergence of societal concerns (Anon, 2013; Cohen, 2012; TheFishSite Newsletter., 2012a; TheFishSite Newsletter., 2012c; Kent, 2014) and unstable market prices (Asche and Bjørndal, 2011; Blank, 2013).

The challenges with qualitative modeling are that the magnitude of responses to perturbations (for example management actions) cannot be quantified, and the approach does not allow the evaluation of the relative strengths of responses in multiple simultaneous perturbations. Additionally, signed digraph 
modeling does not provide for assessment of the impact of transitory dynamics, for example the short-term impact of a media campaign on public perception of the industry.

Whilst a very valuable exploratory tool, care should be taken when modeling not to ignore the complexities of cultural value systems, and the potential impact of the external environment in shaping human experiences and economic activity, as these can lead to management decisions with insufficient context (Dambacher et al., 2007; Dinno., 2007). This observation is particularly pertinent to salmon aquaculture where sustainability credentials can impact on human purchasing preferences or emerging consumer concerns (Diana, 2009; Allsopp et al., 2008; Cousteau, 2016).

\section{Conclusion}

Through examining the interaction of technology and socio-economic variables associated with commercial Atlantic salmon aquaculture, qualitative signed digraph modeling provided an enhanced causal understanding of the dynamics and feedbacks that drive and regulate this industry. The research demonstrated the utility of this modeling approach as a tool to support strategic aquaculture development decision-making, with particular reference to expansion and adoption of alternative grow-out technologies.

The behavioral dynamics and responses predicted by the modeling were generally consistent with industry behavior, and were supported by empirical evidence. The results: 
- Underlined the benefits of strategically understanding the dynamics of demand growth drivers;

- Emphasized the pivotal requirement for an industry to address any societal concerns early to both maintain demand and prevent the industry potentially moving into a cycle of 'boom and bust' in the later stages of its development; and

- Indicated that the levels of ambiguity (uncertainty) are lowest with expansion offshore and highest with the adoption of land-based RAS growout technology.

This generic salmon aquaculture model could be readily applied to the culture of other finfish species, or to the farming of prawns, bivalves and macro-algae. Broader adoption of signed digraph qualitative models would greatly assist aquaculture policy makers, strategic planners and practitioners in evaluating the consequence of adoption of alternative production strategies and technologies, and in predicting how the aquaculture production business environment might holistically respond to such changes.

\section{ACKNOWLEDGEMENTS}

The authors would like to thank the international aquaculture community for their active engagement in this research. The information and support that they provided was invaluable in developing an understanding of the business environment and for ground-truthing the research finding. Thanks also to the Editor and anonymous reviewers for their guidance and insightful comments in the preparation of this paper. Funding for the research was embedded with the 
Australian Seafood Cooperative Research Centre's (CRC) future aquaculture production programme (Project 2011-735). 


\section{REFERENCES}

1. Allsopp, M., Johnston, P. and Santillo, D. (2008). Challenging the aquaculture industry on sustainability (JN 106) (p. 24). Amsterdam, The Netherlands.

2. Anon. (2013). Fisherman, NGOs question Ireland's aquaculture expansion. Undercurrentnews. http://www.undercurrentnews.com/2013/07/19/fishermenngos-question-irelands-aquaculture-expansion/.

3. Arnot, C. (2014, 7-11 June). Ethics, values and science - building trust in today's aquaculture. Paper presented at the World Aquaculture Conference, Adelaide, Australia.

4. Asche F. 2008. Farming the sea. Marine Resource Economics 23(4): 527-547.

5. Asche, F. and Bjørndal, T. (2011) The economics of salmon aquaculture, Second edition Wiley-Blackwell, Oxford, UK.

6. Benaroch, M. and Dhar, V. (1995) Controlling the complexity of investment decisions using qualitative reasoning techniques. Decison Support Systems, 15(2), 115-131.

7. Benetti, D.D., Benetti, G.I., Rivera, J.A., Sardenberg, B. and O'Hanlon, B. (2010) Site selection criteria for open ocean aquaculture. Marine Technology Society Journal, 44(3), 22-35.

8. Blank, C. (2013). Farmed salmon remains a tough market. http://www.seafoodsource.com/news/aquaculture/13929-farmed-salmon-remainsa-tough-market.

9. Bodini, A., Ricci, A. and Viaroli, P. (2000) A multimethodological approach for the sustainable management of perifluvial wetlands of the Po River (Italy). Environmental management, 26 (1), 59-72.

10. Bostock, J., McAndrew, B., Richards, R., Jauncey, K., Telfer, T., Lorenzen, K., Little, D., Ross, L., Handisyde, N. and Gatward, I. (2010) Aquaculture: global status and trends. Philosophical Transactions of the Royal Society of Biological Sciences, 365(1554), 2897-2912.

11. Boulet, D., Struthers, A. and Gilbert, E. (2010). Feasibility study of closedcontainment options for the British Columbia aquaculture industry (p. 51). Aquaculture Management Directorate Fisheries \& Oceans, Ottawa, Canada.

12. Brækkan EH, Thyholdt SB. 2014. The bumpy road of demand growth-an application to Atlantic salmon. Marine Resource Economics 29(4): 339-350.

13. Brigolin, D., Pastres, R., Tomassetti, P. and Porrello, S. (2010) Modelling the biomass yield and the impact of seabream mariculture in the Adriatic and Tyrrhenian Seas (Italy). Aquaculture International, 18(2), 149-163.

14. Broch, O.J., Ellingsen, I.H., Forbord, S., Wang, X., Volent, Z., Alver, M.O., Handa, A., Andresen, K., Slagstad, D., Reitan, K.I., Olsen, Y. and Skjermo, J. (2013) Modelling the cultivation and bioremediation potential of the kelp Saccharina latissima in close proximity to an exposed salmon farm in Norway. Aquaculture Environment Interactions, 4(2), 187-206.

15. Bronnmann J, Asche F. 2017. Sustainable Seafood From Aquaculture and Wild Fisheries: Insights From a Discrete Choice Experiment in Germany. Ecological Economics 142: 113-119.

16. Christensen, C.M. (1997) The innovator's dilemma: When new technologies cause great firms to fail. Harvard Business School Press, Cambridge, MA, USA.

17. Cohen, B.I. (2012). Commission of inquiry into the decline of Sockeye Salmon in the Fraser River (Canada) - Final Report October 2012: Vol 2 Causes of deline (p. 207). Public Works and Government Services, Ottawa, Canada.

18. Cousteau, J.M. (2016). The future of sustainable fish farming. http://www.oceanfutures.org/news/blog/future-sustainable-fish-farming. 
19. Dambacher, J.M., Brewer, D.T., Dennis, D.M., Macintyre, M. and Foale, S. (2007) Qualitative modelling of gold mine impacts on Lihir Island's socioeconomic system and reef-edge fish community. Environmental Science and Technology, 41(2), 55562.

20. Dambacher, J.M., Gaughan, D.J., Rochet, M.-J., Rossignol, P.A. and Trenkel, V.M. (2009) Qualitative modelling and indicators of exploited ecosystems. Fish and Fisheries, 10(3), 305-322.

21. Dambacher, J.M., Li., H.W. and Rossignol, P.A. (2003) Qualitative predictions in model ecosystems. Ecological Modelling, 161(1-2), 79-93.

22. Dambacher., J.M., Li., H.W. and Rossignol., P.A. (2002) Relevance of community structure in assessing indeterminacy of ecological predictions. Ecology, 83(5), 13721385.

23. Dambacher, J.M., Li, H.W. and Rossignol, P.A. (2005). Supplement 1, Version 3: Maple $V$ program commands for qualitative and symbolic analysis of the community matrix. Ecological Archives E083-022-S1 Available at: http://esapubs.org/archive/ecol/E083/022/suppl-1.htm.

24. Diana, J.S. (2009) Aquaculture production and biodiversity conservation. Bioscience, 59(1), 27-38.

25. Dinno., A. (2007) Loop analysis of causal feedback in epidemiology: An illustration relating to urban neighborhoods and resident depressive experiences. Social Science and Medicine, 65(10), 2043-2057.

26. FAO. (1996). Rapid rural appraisal, participatory rural appraisal and aquaculture (Fisheries and Aquaculture Technical Paper 358) (p. 109). FAO, Rome, Italy.

27. Fisheries and Oceans Canada. (2010). National aquaculture strategic action plan initiative: 2011-2015 (DFO/2010-1692) (p. 15). Fisheries and Oceans Canada, Ottawa, Canada.

28. Hanson, R. (2014). Tasmanian salmon producer Huon Aquaculture plans big expansion. http://www.themercury.com.au/news/tasmania/tasmanian-salmonproducer-huon-aquacultre-plans-big-expansion-off-back-of-asx-listing/storyfnj4f7k1-1227090159573.

29. Henderson, A., Gamito, S., Karakassis, I., Pederson, P. and Smaal, A. (2001) Use of hydrodynamic and benthic models for managing environmental impacts of marine aquaculture. Journal of Applied Ichthyology, 17(4), 163-172.

30. Hosack, G.R., Hayes, K.R. and Dambacher, J.M. (2008) Assessing model structure uncertainty through an analysis of system feedback and Bayesian networks. Ecological Applications, 18(4), 1070-1082.

31. Hossain, M.S., Chowdhury, S.R., Das, N.G., Sharifuzzaman, S.M. and Sultana, A. (2009) Integration of GIS and multicriteria decision analysis for urban aquaculture development in Bangladesh. Landscape and Urban Planning, 90(3), 119-133.

32. Hughes, A.D. and Kelly, M.S. (2011). Integrated Multi-Trophic Aquaculture (p. 15). Scottish Association for Marine Science, Oban, Scotland.

33. Jervell, E.E. (2014). Fish farming explores deeper, cleaner waters. http://www.wsj.com/articles/SB10001424052702303887804579503330588540974.

34. Kent, M. (2014). Sea-pen rumours ring alarm bells. http://tasmaniantimes.com/index.php?/pr-article/sea-pen-rumours-rings-alarmbells.

35. King, A.S., Elliott, N.G., James, M.A., MacLeod, C.K. and Bjorndal, T. (2016) Technology selection - the impact of economic risk on decision making. Aquaculture Economics \& Management, 1-27. 
36. Kirchhoff, N.T., Rough, K.M. and Nowak, B.F. (2011) Moving cages further offshore: Effects on southern bluefin tuna, T. maccoyii, parasites, health and performance. PLoS One, 6(8), 8.

37. Klinger, D. and Naylor, R. (2012) Searching for solutions in aquaculture: Charting a sustainable course. Annual Review of Environment and Resources, 37(1), 247-276.

38. Kobayashi M, Msangi S, Batka M, Vannuccini S, Dey MM, Anderson JL. 2015. Fish to 2030: the role and opportunity for aquaculture. Aquaculture economics \& management 19(3): 282-300.

39. Kumar G, Engle CR. 2016. Technological advances that led to growth of shrimp, salmon, and tilapia farming. Reviews in Fisheries Science \& Aquaculture 24(2): 136152.

40. Kuterra. (2014). Sustainability has landed http://www.kuterra.com.

41. Levins, R. (1966) The strategy of model building in population biology. American Scientist, 54(4), 421-431.

42. Levins., R. (1974) The qualitative analysis of partially specified systems. Annals of the New York Academy of Sciences, 123-138.

43. Li, H.W. and Moyle, P.B. (1981) Ecological analysis of species introductions into aquatic systems. Transactions of the American Fisheries Society, 110(6), 772-782.

44. Liu P, Lien K, Asche F. 2016. The impact of media coverage and demographics on the demand for Norwegian salmon. Aquaculture Economics \& Management 20(4): 342356.

45. Liu, Y. and Sumaila, U.R. (2007) Economic analysis of netcage versus sea-bag production systems for salmon aquaculture in British Columbia. Aquaculture Economics \& Management, 11(4), 371-395.

46. Loiselle, S., Hull, V., Permingeat, E., Falcucci, M. and Rossi, C. (2002) Qualitative models to predict impacts of human interventions in a wetland ecosystem. Web Ecology, 3, 56-69.

47. Maskin, E.D. (2008) Mechanism Design: How to implement social goals. American Economic Review, 93(3), 567-576.

48. Metcalf, S.J., Gaughan, D.J. and Shaw, J. (2009). Conceptual models for ecosystem based fisheries management (EBFM) in Western Australia (Fisheries Research Report No.194) (p. 36). Department of Fisheries, W.A., Perth, Australia.

49. Muir, J.F., Brugere, C., Young, J.A. and Stewart, J.A. (1999) The solution to pollution? The value and limitations of environmental economics in guiding aquaculture development Aquaculture Economics \& Management, 3(1), 43-57.

50. Murray, A.G. (2001) The use of simple models in the design and calibration of a dynamic 2D model of a semi-enclosed Australian bay. Ecological Modelling, 136(1), 15-30.

51. Murray, C. and McDonald, G. (2010). Aquaculture economic impact in the Auckland Region (Technical Report 2010/009) (p. 47). Auckland Regional Council, Auckland, NZ.

52. NT Department of Resources - Fisheries Group. (2011). Aquaculture strategic plan 2011-2015 (p. 1). Northern Teritory Government, Darwin, Australia.

53. Nunoo, F.K.E., Asamoah, E.K. and Osei-Asare, Y.B. (2014) Economics of aquaculture production: a case study of pond and pen culture in southern Ghana. Aquaculture Research, 45(4), 675-688.

54. Ortiz, M. and Levins, R. (2011) Re-stocking practices and illegal fishing in northern Chile (SE Pacific coast): A study case. Oikos, 120 (9), 1402-1412.

55. Osmundsen TC, Almklov P, Tveterås R. 2017. Fish farmers and regulators coping with the wickedness of aquaculture. Aquaculture Economics \& Management 21(1): 163183. 
56. Puccia., C.J. and Levins, R. (1985) Qualitative modeling of complex systems: An introduction to loop analysis and time averaging. Harvard University Press, Cambridge, USA.

57. Quirk, J. and Ruppert, R. (1965) Qualitative economics and the stability of equilibrium. The Review of Economic Studies, 32(4), 311-326.

58. Ridler, N., Wowchuk, M., Robinson, B., Barrington, K., Chopin, T., Robinson, S., Page, F., Reid, G., Szemerda, M., Sewuster, J. and Boyne-Travis, S. (2007) Integrated MultiTrophic Aquaculture (IMTA): A potential strategic choice for farmers. Aquaculture Economics \& Management, 11(1), 99-110.

59. Ryan, J., Jackson, D. and Maguire, D. (2007). Offshore aquaculture development in Ireland 'Next Steps' (p. 35). Bord Lascaigh Mhara, Dublin, Ireland.

60. Samuelson, P.A. (1983) Foundations of economic analysis. Harvard University Press, Cambridge, USA.

61. Sha S, Santos JI, Roheim CA, Asche F. 2015. Media coverage of PCB contamination of farmed salmon: The response of US import demand. Aquaculture economics \& management 19(3): 336-352.

62. Shuve, J., Caines, E., Ridler, N., Chopin, T., Reid, G.K., Sawhney, M., Lamontagne, J., Szemerda, M., Marvin, R., Powell, F., Robinson, S. and Boyne-Travis, S. (2009) Survey finds consumers support integrated multitrophic aquaculture - Effective marketing concept key. Global Aquaculture Advocate, Mar/Apr, 22-23.

63. TheFishSite Newsletter. (2012a). Concerns over net pen expansion. http://www.thefishsite.com/fishnews/16675/concern-over-salmon-open-net-penexpansion.

64. TheFishSite Newsletter. (2012b). Petition: Investigation of wild salmon protection. http://www.thefishsite.com/fishnews/16411/petition-investigation-of-wild-salmonprotection.

65. TheFishSite Newsletter. (2012c). Prevention of expansion into Bantry Bay. http://www.thefishsite.com/fishnews/18591/all-irelands-166-tds-contacted-bycampaigners.

66. Uchida H, Onozaka Y, Morita T, Managi S. 2014. Demand for ecolabeled seafood in the Japanese market: A conjoint analysis of the impact of information and interaction with other labels. Food Policy 44: 68-76.

67. Waite, R., Beveridge, M., Brummett, R., Castine, S., Chaiyawannakarn, N., Kaushik, S., Mungkung, R., Nawapakpilai, S. and Phillips, M. (2014). Improving productivity and environmental performance of aquaculture (Working Paper June 2014) (p. 60). World Resources Institute, Washington, DC, USA. 

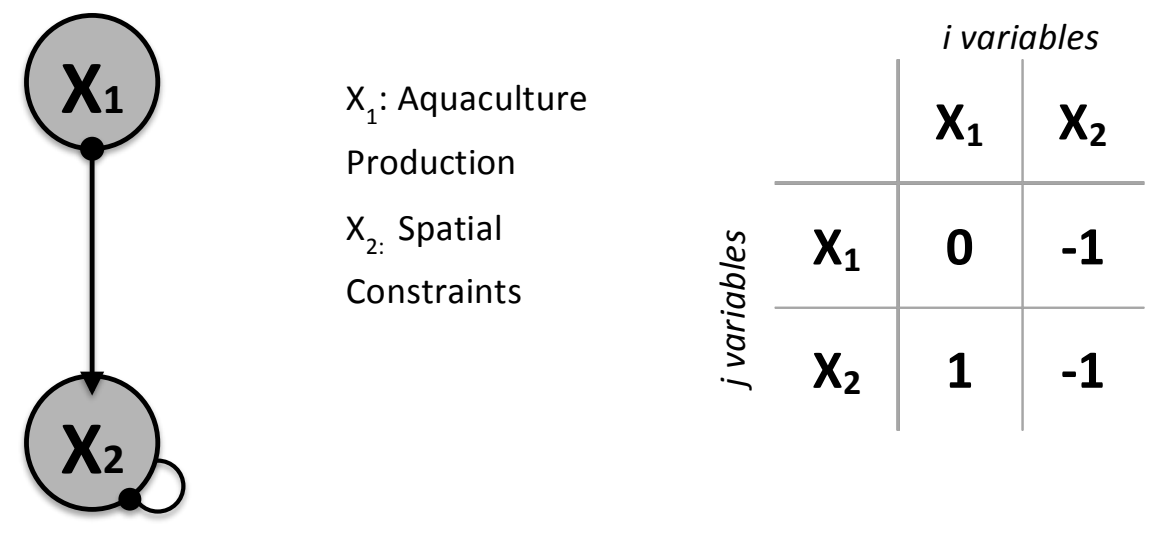


\begin{tabular}{|c|c|c|c|c|}
\hline & $\frac{\Xi}{\sigma}$ & 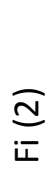 & $\begin{array}{l}\overparen{m} \\
\stackrel{\varrho}{\varepsilon} \\
\underline{\underline{n}}\end{array}$ & $\begin{array}{l}\overparen{\Xi} \\
\check{c} \\
0 \\
\text { ல }\end{array}$ \\
\hline $\mathrm{Aq}(1)$ & 0 & 0 & 0 & -1 \\
\hline $\mathrm{Fi}(2)$ & 0 & -1 & 0 & 0 \\
\hline $\operatorname{Imp}(3)$ & 0 & 0 & -1 & 0 \\
\hline Sp Con (4) & 1 & 0 & 0 & -1 \\
\hline
\end{tabular}

Community Matrix

\begin{tabular}{|c|c|c|c|c|}
\hline & $\frac{\vec{\sigma}}{\frac{\sigma}{4}}$ & $\frac{\widetilde{\simeq}}{i ᄑ}$ & $\begin{array}{l}\frac{\widehat{m}}{\varrho} \\
\underline{\underline{\varepsilon}}\end{array}$ & $\begin{array}{l}\overparen{\Xi} \\
\check{c} \\
\dot{U} \\
\stackrel{0}{n}\end{array}$ \\
\hline $\mathrm{Aq}(1)$ & 10 & -5 & -5 & -10 \\
\hline $\mathrm{Fi}(2)$ & -5 & 41 & -14 & 5 \\
\hline Imp (3) & 0 & -11 & 44 & 0 \\
\hline Sp Con (4) & 25 & -7 & -7 & 30 \\
\hline
\end{tabular}

Adjoint Matrix

Key: $\mathrm{Aq}(1)$ Salmon aquaculture production, $\mathrm{Fi}(2)$ Commercial salmon fisheries production Imp (3) Imports of salmon, Sp Con (4) Marine spatial constraints to sea-pen production 


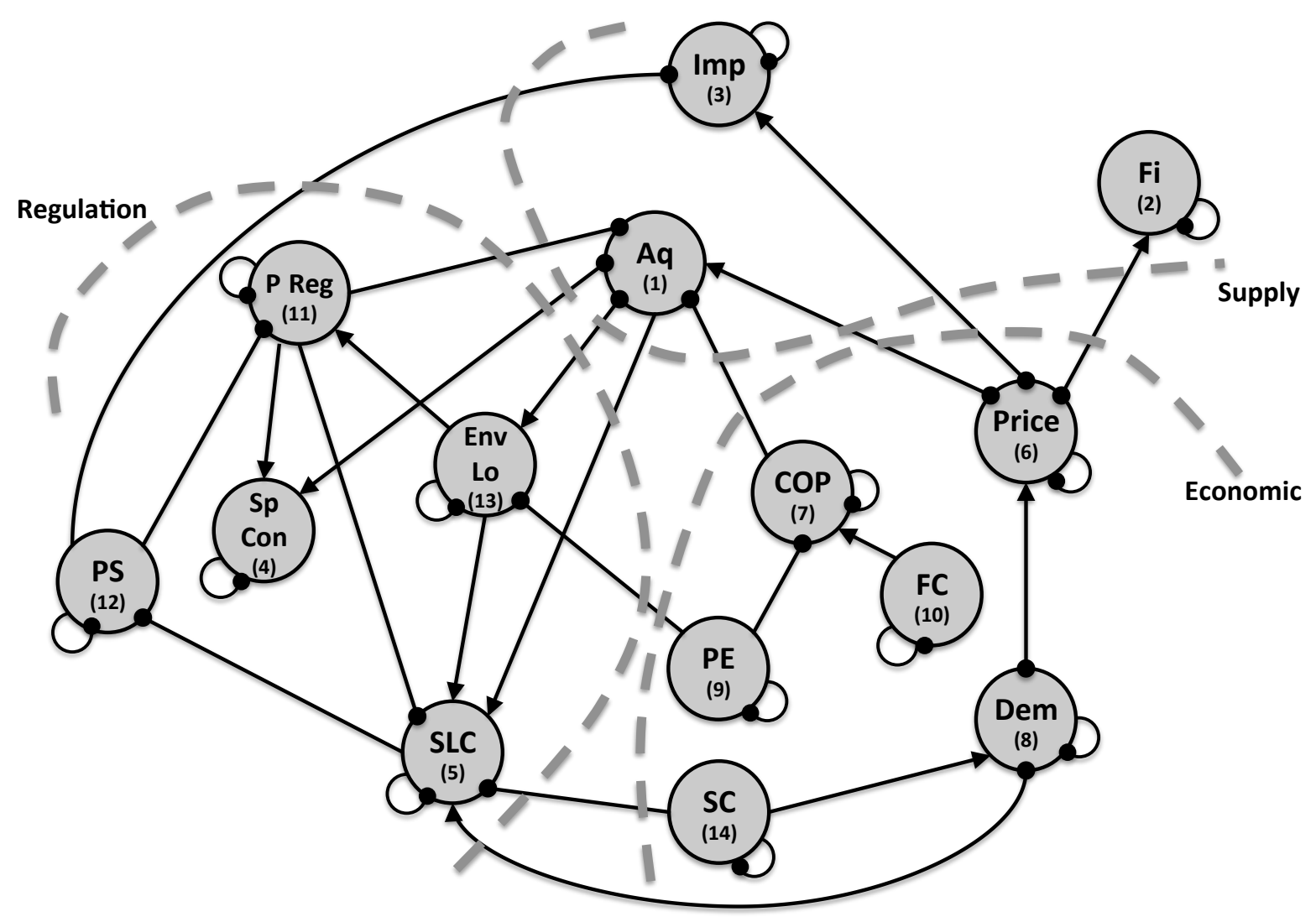




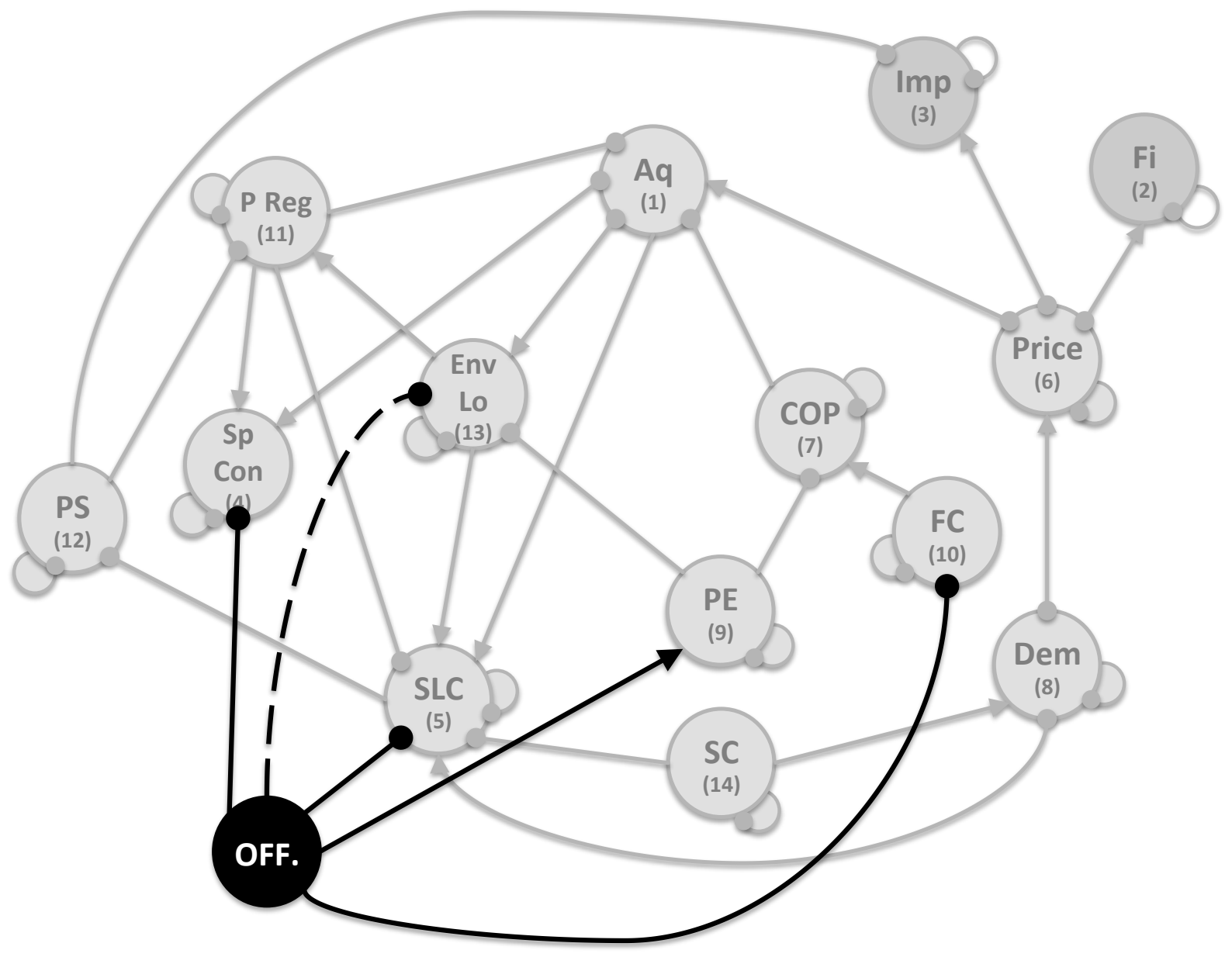




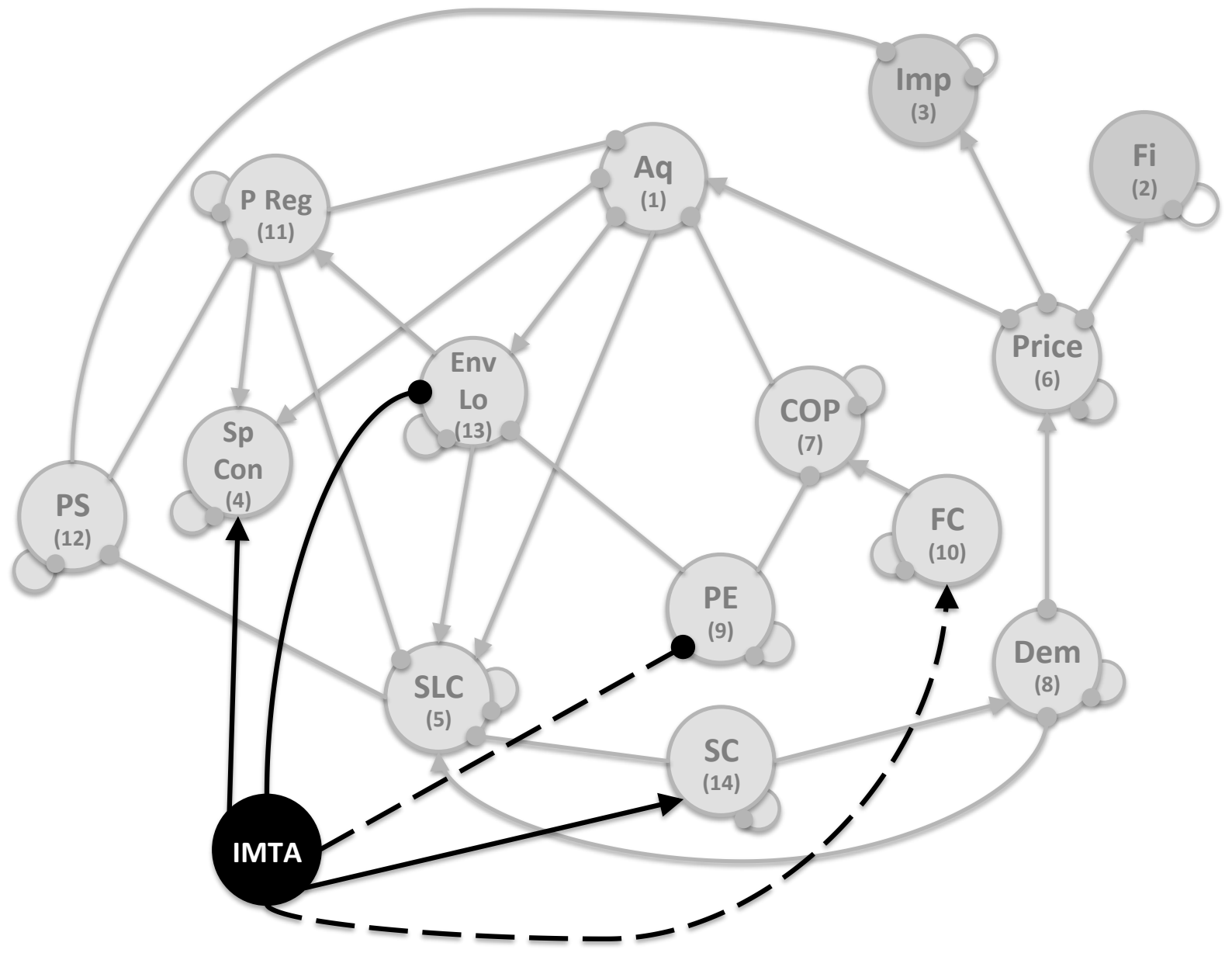




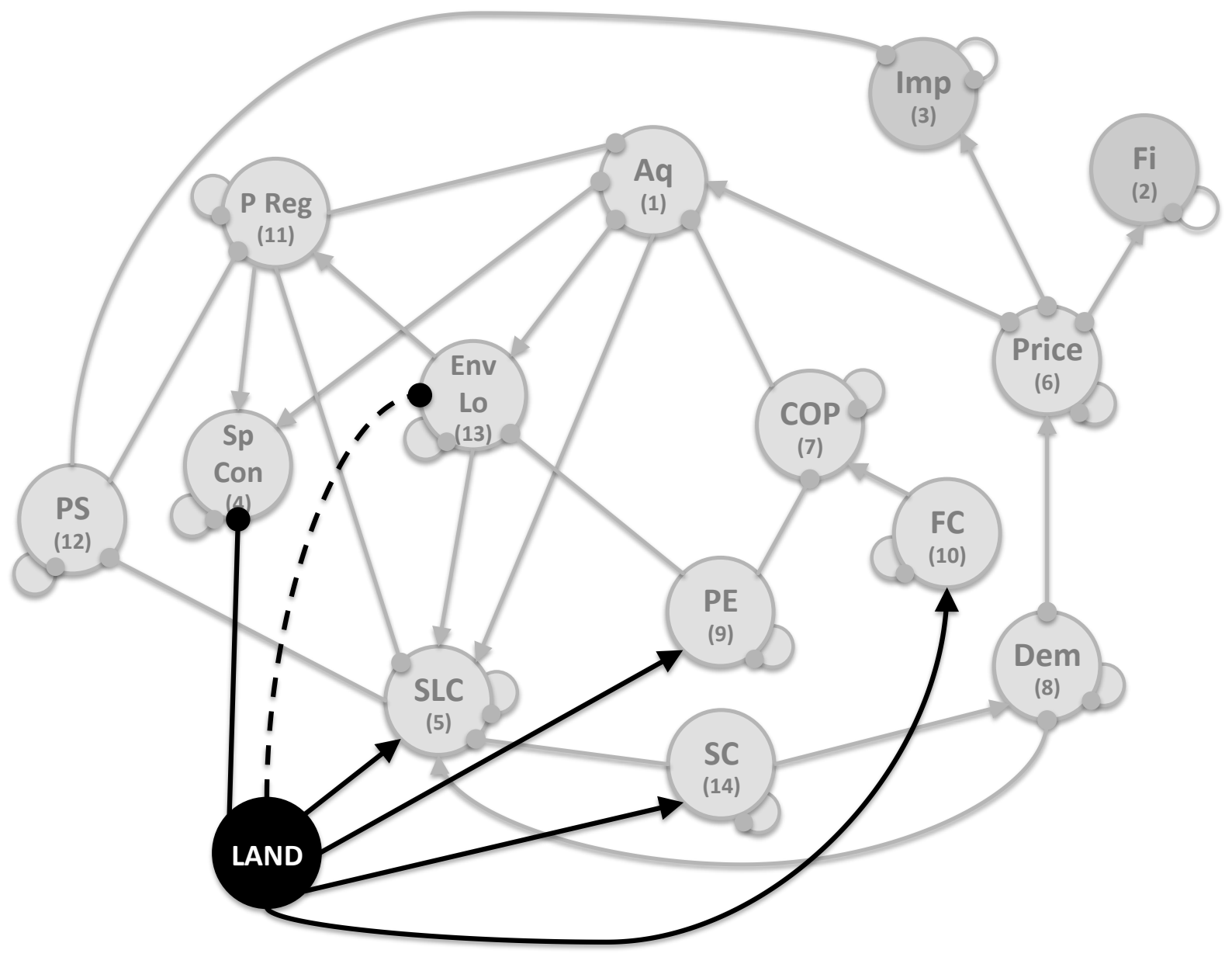




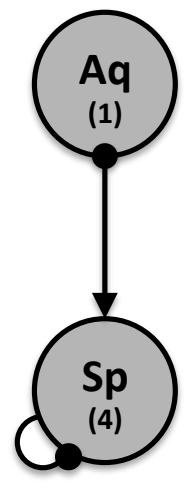

Spatial Regulation
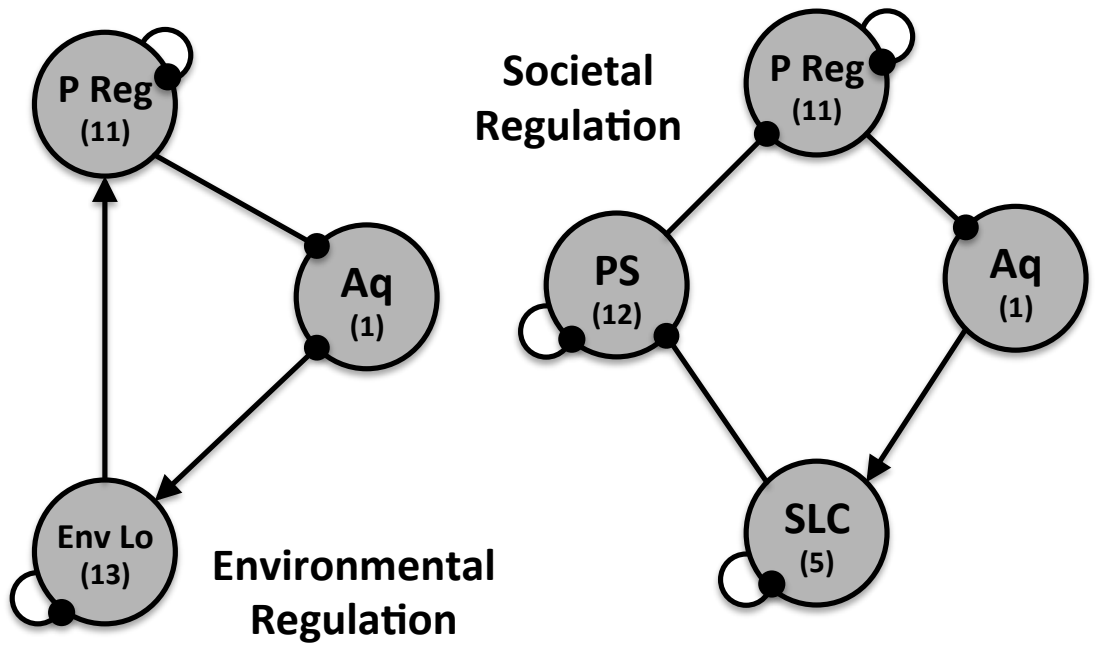


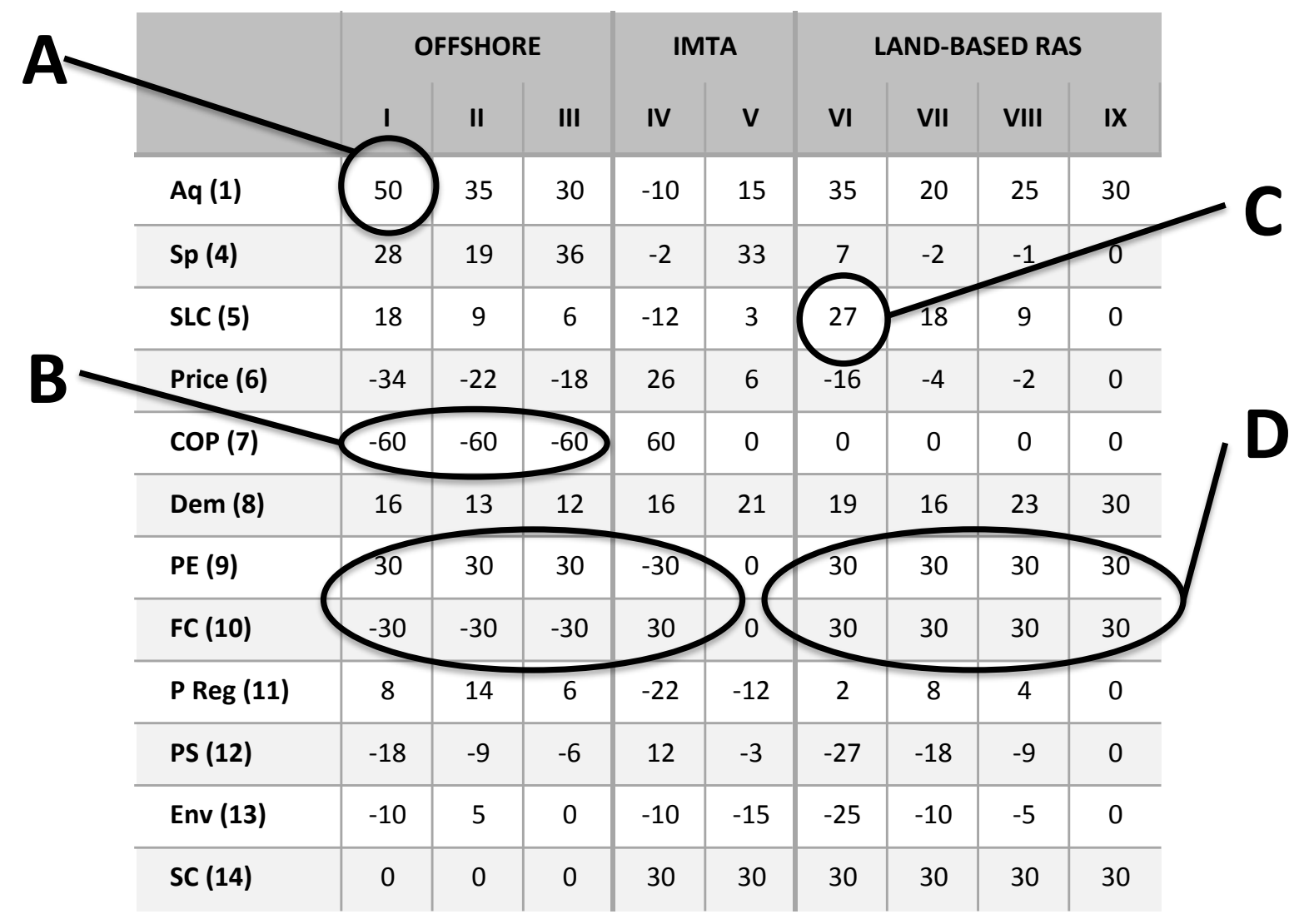

Note: Adjoint matrix values may be used as general benchmark for expected system behavior. Caution should be taken when deriving quantitative comparisons of response strengths (Dambacher et al., 2003). 

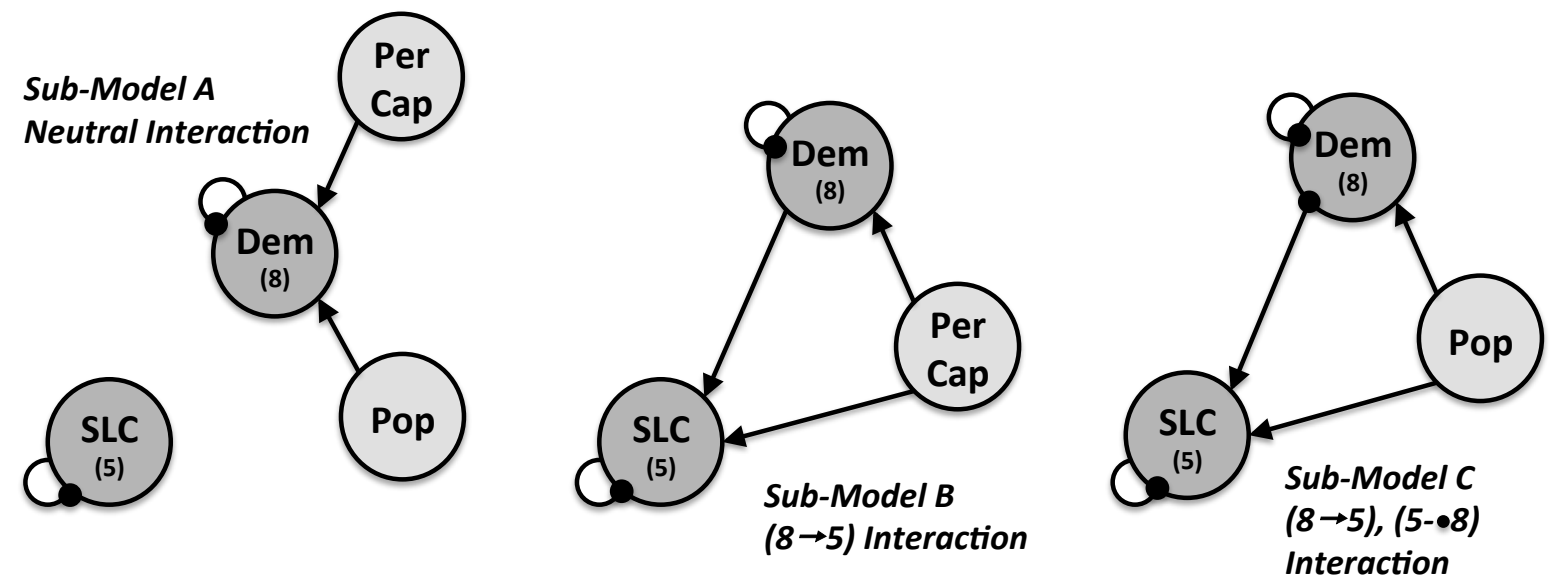
Figure 1: A stylized example of Signed digraph and 'Community' matrix representations for aquaculture spatial regulation. Positive direct interactions / effects are shown by arrows (or +1 in matrix), and negative direct interactions by lines ending in a circle (or -1 ). Self-effects are depicted by lines returning to the source variable, which may be either positive or negative. Perturbations (increases) occur down the matrix columns, whilst responses (predictions) to perturbations are read across rows.

Figure 2: Community and Adjoint matrix representations of four variables within a 14 variable system (depicted in Appendix A). The Community matrix identifies the direct interactions between the variables. The Adjoint matrix shows the direction of change (increase or decrease) and the net number of effects (direct and indirect) that contribute to a variable's response.

Figure 3: Signed digraph model of salmon aquaculture's business environment, with regulation, economic and supply sub-sectors identified. Each of the 14 variables is represented by a grey circle, links ending in an arrow denote a positive direct effect from one variable to another, links ending in a filled circle denote a negative direct effect, and a link connecting a variable to itself denotes a self-effect. All changes illustrate the effect of a positive input to the variables, and are described in Table 3.

Figure 4: Signed digraph representation of a simultaneous perturbation to aquaculture production through adopting an Offshore (OFF) expansion strategy. The direct effect on environmental loadings (EnvLo), depicted by the dashed-line, was evaluated in perturbation scenario I, and excluded in scenarios II and III (Table 4), and the negative spatial constraint (Sp Con) link omitted in scenario III.

Figure 5: Signed digraph representation of a simultaneous perturbation to Atlantic Salmon aquaculture production through adopting an IMTA (Integrated Multi-trophic Aquaculture) expansion strategy. The dashed-lined refers to direct effects on production efficiency (PE). A financial cost (FC) perturbation was included in scenario IV and excluded in V, Table 4. 
Figure 6: Signed digraph model of a simultaneous perturbation to aquaculture production through adopting land-based RAS. The direct effect on environmental loadings (EnvLo) was evaluated in perturbation scenario VI and the uncertainty associated with obtaining a social license to operate in scenarios VII, VIII and IX (Table 4).

Figure 7: Principal aquaculture production regulation mechanisms. Spatial regulation operates through increased production reducing the availability of sites for expansion. Heightened environmental (biological) loadings impart a regulatory response; and societal concerns induce a tightening of production regulations through political interaction.

Figure 8: Compiled perturbation responses from the scenario Adjoint matrices of the comparative strength of the transmitted direct and indirect feedback cycles from running the Atlantic salmon model with alternative technology adoption options and under specified perturbations (Figures 3 to 5, Table 4 and Appendix B).

Figure 9: Signed digraph sub-models illustrating potential interactions between demand (Dem) and social license challenge (SLC) through population (Pop) and per-capita (Per Cap) driven increases in demand. Sub-model A, represents where no societal concerns materialize as population and per capita consumption grow. Sub-model B scenario is where rising per capita consumption, driven by an increasing affluent consumer base, is accompanied with heightened concerns over the impact of aquaculture; however there is (as yet) no impact on demand. In sub-model $\mathrm{C}$ demand growth driven by an aging population is accompanied by a rise in social license challenges, which in turn acts to reduce demand. 

Table 1: Breakdown of interview participants showing the principal focus of the discussion, organisational category, country, and position or level.

\begin{tabular}{|l|c|}
\hline \multicolumn{1}{|c|}{ Interview Focus } & 27 \\
\hline Business Environment & 12 \\
\hline Economics & 25 \\
\hline Technology - Closed Containment & 17 \\
\hline Technology - Extractive Aquaculture & 7 \\
\hline Technology - Fish Welfare Biology & 41 \\
\hline Technology - Sea Pens & \\
\hline Organisation Category & 40 \\
\hline Aquaculture Producer & 20 \\
\hline Equipment Manufacturer & 6 \\
\hline ENGO & 19 \\
\hline Policy or Regulatory & 59 \\
\hline Retailer & \\
\hline Science (Academic and R\&D) & \\
\hline
\end{tabular}

\begin{tabular}{|c|c|}
\hline \multicolumn{2}{|l|}{ Country } \\
\hline Australia & 8 \\
\hline Canada & 29 \\
\hline Denmark & 3 \\
\hline EU (excl Ireland and Scotland) & 11 \\
\hline Ireland & 7 \\
\hline Norway & 29 \\
\hline Others & 3 \\
\hline Scotland & 26 \\
\hline USA & 13 \\
\hline \multicolumn{2}{|l|}{ Position or Level } \\
\hline Executive or Director & 42 \\
\hline Manager & 39 \\
\hline Officer & 48 \\
\hline
\end{tabular}


Table 2: Definitions of fourteen key variables identified from the mind-mapping exercise (names and numbers are used consistently within all models, and in parentheses in the text).

\section{Variable Number and Name}

\begin{tabular}{|c|c|c|}
\hline $\mathrm{Aq}(1)$ & Aquaculture & $\begin{array}{l}\text { Domestic aquaculture production of Atlantic salmon by a } \\
\text { defined country / region }\end{array}$ \\
\hline Fi (2) & Fisheries & $\begin{array}{l}\text { Commercial fisheries production of Atlantic salmon by a defined } \\
\text { country / region }\end{array}$ \\
\hline Imp (3) & Imports & $\begin{array}{l}\text { Imports of fresh HOG (Head Off Gutted) Atlantic salmon to the } \\
\text { domestic seafood market for a defined country / region }\end{array}$ \\
\hline Sp Con (4) & Spatial Constraints & $\begin{array}{l}\text { Marine spatial constraints due to the availability of leased sea- } \\
\text { water space in which to undertake aquaculture production } \\
\text { using sea-pens }\end{array}$ \\
\hline SLC (5) & Social License Challenge & $\begin{array}{l}\text { Societal challenges derived from approval by local communities } \\
\text { and stakeholders for aquaculture companies to conduct their } \\
\text { business }\end{array}$ \\
\hline Price (6) & Price & $\begin{array}{l}\text { Sales price of fresh Atlantic salmon in the domestic market of } \\
\text { the defined country / region }\end{array}$ \\
\hline COP (7) & Cost of Production & $\begin{array}{l}\text { Aquaculture cost of producing Atlantic salmon in the defined } \\
\text { country / region }\end{array}$ \\
\hline Dem (8) & Demand & Demand for fresh Atlantic salmon in a defined market / country \\
\hline PE (9) & Production Efficiency & $\begin{array}{l}\text { Efficiency associated with biological performance, human } \\
\text { factors and infrastructure }\end{array}$ \\
\hline FC (10) & Finance Cost & $\begin{array}{l}\text { The cost of financing aquaculture production, capital and } \\
\text { operating expenditure }\end{array}$ \\
\hline P Reg (11) & Production Regulations & The statutory framework for the regulation of the industry \\
\hline PS (12) & Political Support & $\begin{array}{l}\text { Government actions that effects aquaculture operations of a } \\
\text { company. May be on local, state, federal or international level }\end{array}$ \\
\hline Env Lo (13) & Environmental Loadings & $\begin{array}{l}\text { Environmental impact of aquaculture sedimentation and } \\
\text { nutrient loadings }\end{array}$ \\
\hline SC (14) & Sustainability Credentials & $\begin{array}{l}\text { Demonstrable sustainability credentials through 'certified' } \\
\text { environmental, community and farm management practices }\end{array}$ \\
\hline
\end{tabular}

\section{Definition}


Table 3: Sign of the direct interactions between the supply, regulation and economic variables influencing salmon aquaculture production (Figure 3), resulting from a positive input to a variable. The numbers corresponding to the variables defined in Table 2.

\begin{tabular}{|c|c|c|c|}
\hline \multicolumn{3}{|c|}{ Direct Effect } & \multirow{2}{*}{ Mechanism } \\
\hline Sign & To & From & \\
\hline+ & 4 & 1 & $\begin{array}{l}\text { Atlantic salmon aquaculture growout operations (1) utilize leased marine sites. Industry growth } \\
\text { reduces the availability of suitable sites, and increases spatial constraints (4). Growth }\end{array}$ \\
\hline+ & 5 & 1 & $\begin{array}{l}\text { will also increase the propensity for social license challenges (5) associated with this expansion } \\
\text { and result in }\end{array}$ \\
\hline+ & 13 & 1 & higher levels of environmental loadings (13). \\
\hline- & 6 & 1 & $\begin{array}{l}\text { The sales price of Atlantic salmon (6) in a market reduces with an increase in aquaculture } \\
\text { production supply (1), together with }\end{array}$ \\
\hline- & 6 & 2 & increased availability of wild caught Atlantic salmon (2), and \\
\hline- & 6 & 3 & greater import volumes (3). \\
\hline- & 1 & 4 & Increased spatial constraints (4) reduce the ability to undertake aquaculture operations (1). \\
\hline- & 8 & 5 & $\begin{array}{l}\text { An increase in societal concerns and challenges (5) with the aquaculture industry would depress } \\
\text { demand (8), and }\end{array}$ \\
\hline- & 12 & 5 & raise political concerns, reducing the level of political support (12). \\
\hline+ & 1 & 6 & $\begin{array}{l}\text { Sustained increase in the sales price of fresh salmon (6) in a market, will act as an incentive for } \\
\text { growth in supply through a combination of increases in aquaculture (1), }\end{array}$ \\
\hline+ & 2 & 6 & commercial fisheries (2) production levels, \\
\hline+ & 3 & 6 & and a rise in imports (3). \\
\hline- & 8 & 6 & Increased price (6) of Atlantic salmon will reduce market demand (8), and \\
\hline+ & 6 & 8 & $\begin{array}{l}\text { increased demand increases price. With demand }(8) \text { for a country being determined through per } \\
\text { capital consumption levels and the overall population size. }\end{array}$ \\
\hline- & 1 & 7 & $\begin{array}{l}\text { Increased aquaculture cost of production (7) will reduce the level of aquaculture production (1) } \\
\text { undertaken, }\end{array}$ \\
\hline- & 7 & 9 & and a rise in production efficiency (9) will reduce the cost of production (7) and \\
\hline- & 13 & 9 & the levels of environmental loadings (13). With \\
\hline+ & 7 & 10 & $\begin{array}{l}\text { higher financial costs (10) associated with capital and operating expenditure increasing the cost } \\
\text { of production (7). }\end{array}$ \\
\hline+ & 5 & 8 & $\begin{array}{l}\text { Increased demand (8) associated with population growth and enhanced disposable income can } \\
\text { result in heighted societal concerns (5) about aquaculture operations. }\end{array}$ \\
\hline- & 1 & 11 & Stricter production regulations (11) act as a brake to reduce aquaculture (1) effort, \\
\hline+ & 4 & 11 & increase spatial constraints (4), and \\
\hline- & 5 & 11 & are likely to reduce the level of societal concerns (5). \\
\hline- & 3 & 12 & $\begin{array}{l}\text { Improved levels of political support (12) will be likely to strengthen import regulations and result } \\
\text { in a fall in import volumes (3), and }\end{array}$ \\
\hline- & 11 & 12 & reduce regulatory constraints $(11)$ and barriers to aquaculture production development. \\
\hline- & 1 & 13 & $\begin{array}{l}\text { Increased environmental loading (13) impacts are likely to result in a reduction of aquaculture } \\
\text { production (1) by individual companies, due to self monitoring }\end{array}$ \\
\hline+ & 5 & 13 & heighten societal concerns (5), and \\
\hline+ & 11 & 13 & increase production regulation pressures (11). \\
\hline- & 5 & 14 & $\begin{array}{l}\text { Improving perceived sustainability credentials (14) will support expansion through reducing } \\
\text { societal concerns (5) and }\end{array}$ \\
\hline+ & 8 & 14 & $\begin{array}{l}\text { strengthening demand (8) through suppression of the positive link from (8) to (5) and the } \\
\text { negative link from (5) to (8) }\end{array}$ \\
\hline
\end{tabular}


Table 4: Technology adoption perturbations scenarios applied to a signed digraph model of Atlantic salmon aquaculture showing expansion type (Offshore, IMTA or Landbased RAS), the reference figure for the appropriate signed digraph (Fig 3-5), perturbation scenario reference number (I to IX), and perturbed variables. A positive perturbation of a variable is indicated by + sign, negative perturbation by - sign, and where a variable is not perturbed by a blank.

\begin{tabular}{|c|c|c|c|c|c|c|c|c|c|}
\hline \multirow{2}{*}{$\begin{array}{l}\text { Expansion Type } \\
\text { Signed Digraph Figure } \\
\text { Perturbation Scenario Ref\# }\end{array}$} & \multicolumn{3}{|c|}{$\begin{array}{c}\text { OFFSHORE } \\
\text { Figure } 3\end{array}$} & \multicolumn{2}{|c|}{$\begin{array}{c}\text { IMTA } \\
\text { Figure } 4\end{array}$} & \multicolumn{4}{|c|}{$\begin{array}{c}\text { LAND-BASED RAS } \\
\text { Figure } 5\end{array}$} \\
\hline & I & II & III & IV & V & VI & VII & VIII & IX \\
\hline Sp Con (4) & - & - & & + & + & - & - & - & - \\
\hline SLC (5) & - & - & - & & & + & + & & - \\
\hline PE (9) & + & + & + & - & & + & + & + & + \\
\hline FC (10) & - & - & - & + & & + & + & + & + \\
\hline Env Lo (13) & - & & & - & - & - & & & \\
\hline SC (14) & & & & + & + & + & + & + & + \\
\hline
\end{tabular}


Table 5: Categorized feedback cycles for the signed digraph models, identifying the process, feedback sign, constituent variables and links. The cycles have been allotted arbitrary starting points of aquaculture production (1), sales price (6) and societal concerns (5). Variables defined and numbered as in Table 2.

\begin{tabular}{|c|c|c|c|}
\hline Feedback Cycle Category & Feedback Cycles & Cycle Variables and links & $\begin{array}{c}\text { Feedback } \\
\text { Sign }\end{array}$ \\
\hline \multirow{4}{*}{ Supply and Demand } & Aquaculture Supply & $6 \rightarrow 1 \rightarrow 6$ & $(-)$ \\
\hline & Fisheries Supply & $6 \rightarrow 2 \rightarrow 6$ & $(-)$ \\
\hline & Import Supply & $6 \rightarrow 3 \rightarrow 6$ & $(-)$ \\
\hline & Demand - Price & $6 \rightarrow 8 \rightarrow 6$ & $(-)$ \\
\hline \multirow{4}{*}{ Regulation } & Spatial control & $1 \rightarrow 4 \rightarrow 1$ & $(-)$ \\
\hline & Env Lo Direct & $1 \rightarrow 13 \rightarrow 1$ & $(-)$ \\
\hline & Env Lo through Production Regulations & $1 \rightarrow 13 \rightarrow 11 \rightarrow 1$ & $(-)$ \\
\hline & Env Lo through Regulations \& spatial & $1 \rightarrow 13 \rightarrow 11 \rightarrow 4 \rightarrow 1$ & $(-)$ \\
\hline \multirow{4}{*}{ Societal - Demand } & Consummer Attitudes & $5 \rightarrow 8 \rightarrow 5$ & $(-)$ \\
\hline & Demand-Price & $5 \rightarrow 8 \rightarrow 6 \rightarrow 1 \rightarrow 5$ & $(-)$ \\
\hline & Demand-Price (Env Lo) & $5 \rightarrow 8 \rightarrow 6 \rightarrow 1 \rightarrow 13 \rightarrow 5$ & $(-)$ \\
\hline & Demand-Price (Pro Reg) & $5 \rightarrow 8 \rightarrow 6 \rightarrow 1 \rightarrow 13 \rightarrow 11 \rightarrow 5$ & $(+)$ \\
\hline \multirow{7}{*}{ Societal - Political (Regulatory) } & Demand via Socio-Political & $5 \rightarrow 12 \rightarrow 11 \rightarrow 1 \rightarrow 6 \rightarrow 8 \rightarrow 5$ & $(-)$ \\
\hline & Production via Socio-Political and space & $5 \rightarrow 12 \rightarrow 11 \rightarrow 4 \rightarrow 1 \rightarrow 5$ & $(-)$ \\
\hline & Env.Lo. via Socio-Political ans space & $5 \rightarrow 12 \rightarrow 11 \rightarrow 4 \rightarrow 1 \rightarrow 13 \rightarrow 5$ & $(-)$ \\
\hline & Demand via Socio-Political and Env.Lo & $5 \rightarrow 12 \rightarrow 11 \rightarrow 4 \rightarrow 1 \rightarrow 6 \rightarrow 8 \rightarrow 5$ & $(-)$ \\
\hline & Socio-Political & $5 \rightarrow 12 \rightarrow 11 \rightarrow 5$ & $(-)$ \\
\hline & Production via Socio-Political & $5 \rightarrow 12 \rightarrow 11 \rightarrow 1 \rightarrow 5$ & $(-)$ \\
\hline & Demand via Socio-Political ans Env.Lo. & $5 \rightarrow 12 \rightarrow 11 \rightarrow 1 \rightarrow 13 \rightarrow 5$ & $(-)$ \\
\hline \multirow{4}{*}{ Societal - Political (Imports) } & Societal-Demand via Imports & $5 \rightarrow 12 \rightarrow 3 \rightarrow 6 \rightarrow 8 \rightarrow 5$ & $(+)$ \\
\hline & Societal - Prod.Vol via Imports & $5 \rightarrow 12 \rightarrow 3 \rightarrow 6 \rightarrow 1 \rightarrow 5$ & $(-)$ \\
\hline & Societal - Env.Lo via Imports & $5 \rightarrow 12 \rightarrow 3 \rightarrow 6 \rightarrow 1 \rightarrow 13 \rightarrow 5$ & $(-)$ \\
\hline & Societal - P. Reg via Imports & $5 \rightarrow 12 \rightarrow 3 \rightarrow 6 \rightarrow 1 \rightarrow 13 \rightarrow 11 \rightarrow 5$ & $(+)$ \\
\hline & & Number of Loops & 23 \\
\hline
\end{tabular}


Table 6: Predicted sign responses for twelve key variables from running the Atlantic salmon model with alternative technology adoption options and under specified perturbations (Figures 3 to 5, and Table 4). Ambiguous predictions with a relatively high probability of sign determinacy (>0.85) are enclosed in parentheses; a "?" denotes those with a low probability where knowledge about the relative interaction would be required to determine the response direction; and a sign encased within square brackets depicts where a supporting condition, referenced by the superscript, has been used to interpret the lower probability ambiguity. A zero indicates no response predicted.

\begin{tabular}{|c|c|c|c|c|c|c|c|c|c|}
\hline & \multicolumn{3}{|c|}{ OFFSHORE } & \multicolumn{2}{|c|}{ IMTA } & \multicolumn{4}{|c|}{ LAND-BASED RAS } \\
\hline & 1 & II & III & IV & v & VI & VII & VIII & IX \\
\hline Aquaculture (1) & + & + & + & $?$ & $(+)$ & {$[+]^{\mathrm{a}}$} & {$[+]^{\mathrm{a}}$} & {$[+]^{\mathrm{a}}$} & {$[+]^{a}$} \\
\hline Space Constraints (4) & $(+)$ & $(+)$ & {$[0]^{b}$} & $?$ & $(+)$ & {$[0]^{b}$} & {$[0]^{\mathrm{b}}$} & {$[0]^{b}$} & {$[0]^{b}$} \\
\hline Social License Challenge (5) & $?$ & $?$ & $?$ & $?$ & $?$ & + & $?$ & $?$ & $?$ \\
\hline Price (6) & $(-)$ & $(-)$ & $(-)$ & $(+)$ & $?$ & $?$ & $?$ & $?$ & $?$ \\
\hline Cost of Production (7) & - & - & - & + & (0) & {$[+]^{C}$} & {$[+]^{C}$} & {$[+]^{\mathrm{C}}$} & {$[+]^{C}$} \\
\hline Demand ( 8 ) & $(+)$ & $(+)$ & $(+)$ & $?$ & $(+)$ & $?$ & $?$ & $(+)$ & $(+)$ \\
\hline Production Efficiency (9) & + & + & + & - & (0) & + & + & + & + \\
\hline Finance Cost (10) & - & - & - & + & (0) & + & + & + & + \\
\hline Production Regulations (11) & $?$ & $(+)$ & $?$ & $(-)$ & $(-)$ & $?$ & $?$ & $?$ & $?$ \\
\hline Political Support (12) & {$[+]^{d}$} & {$[+]^{d}$} & {$[+]^{d}$} & $?$ & $?$ & $(-)$ & $?$ & $?$ & $?$ \\
\hline Environmental Loadings (13) & $?$ & $?$ & $?$ & {$[-]^{\mathrm{e}}$} & $(-)$ & $(-)$ & $?$ & $?$ & $?$ \\
\hline Sustainability Credentials (14) & (0) & (0) & (0) & + & + & + & + & + & + \\
\hline
\end{tabular}

Superscript assumptions and conditions:

a: Adoption of land-based RAS by the industry would be in addition to, rather than a replacement of, the inshore sea-pen production currently undertaken.

b: No impact on the spatial constraints (4) associated with marine inshore sites.

c: Increase in finance cost (10) is greater than economic reduction attributable to production efficiency (9) (King et al., 2016).

$\mathrm{d}$ : The national government would welcome the incremental GDP contribution.

e: Estimates of the dissolved nitrogen inorganic output from a salmon farm that can be absorbed by the IMTA macroalgae range between $2 \%$ to 12\%, (Hughes and Kelly, 2011, Broch et al., 2013). 


\section{APPENDIX A - Salmon Aquaculture Production Signed Digraph Model (Model A)}

\section{Model}

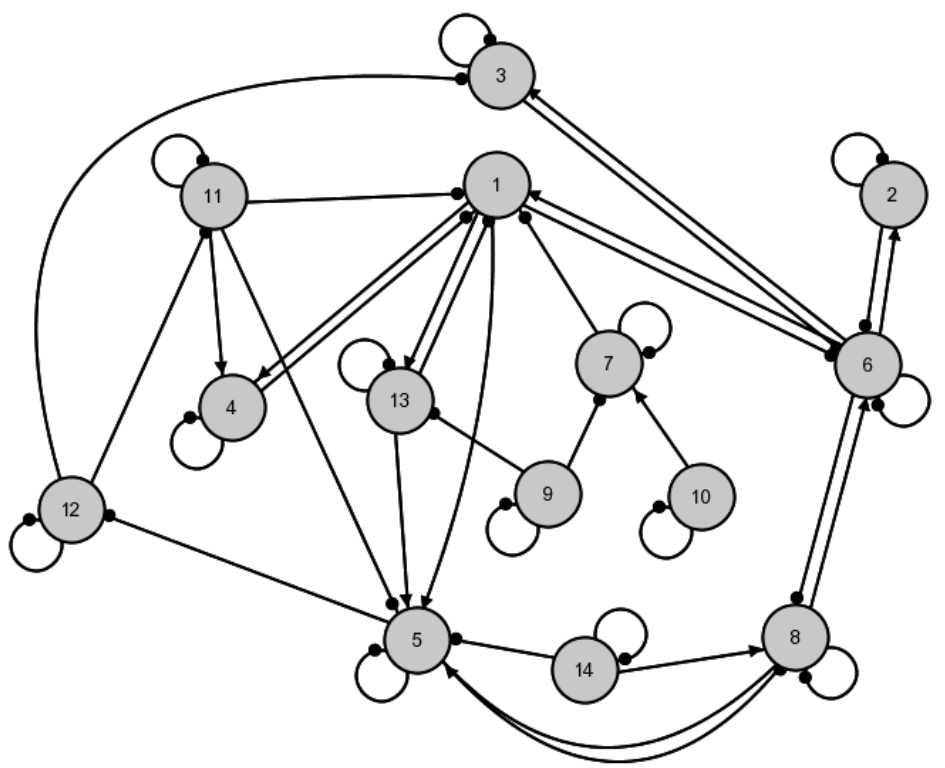

\begin{tabular}{|ll}
\hline Aq (1) & Aquaculture \\
\hline Fi (2) & Fisheries \\
\hline Imp (3) & Imports \\
\hline Sp Con (4) & Spatial Constraints \\
\hline SLC (5) & Social License Challenge \\
\hline Price (6) & Price \\
\hline COP (7) & Cost of Production \\
\hline Dem (8) & Demand \\
\hline PE (9) & Production Efficiency \\
\hline FC (10) & Finance Cost \\
\hline P Reg (11) & Production Regulations \\
\hline PS (12) & Political Support \\
\hline Env Lo (13) & Environmental Loadings \\
\hline SC (14) & Sustainability Credentials \\
\hline
\end{tabular}

Community Matrix

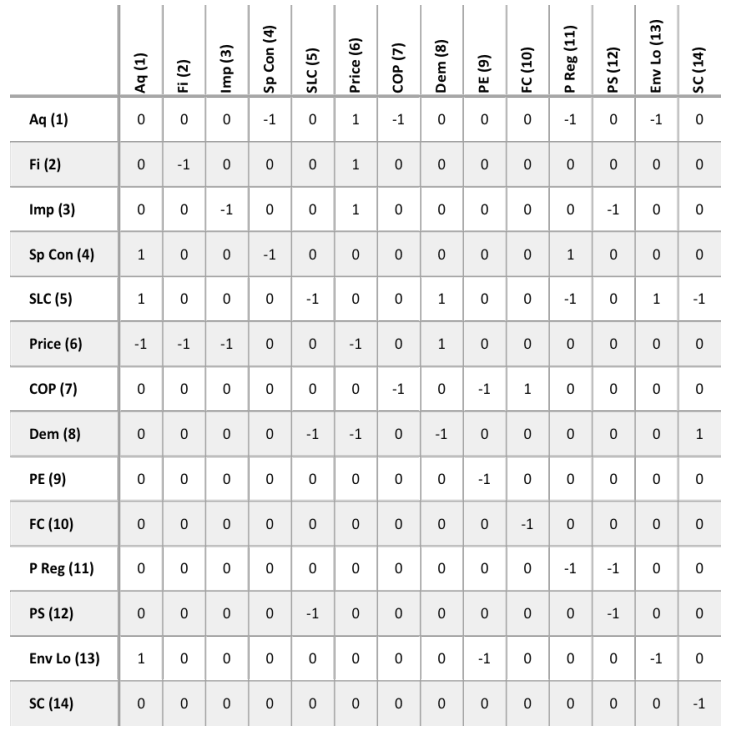

\section{Adjoint Matrix}

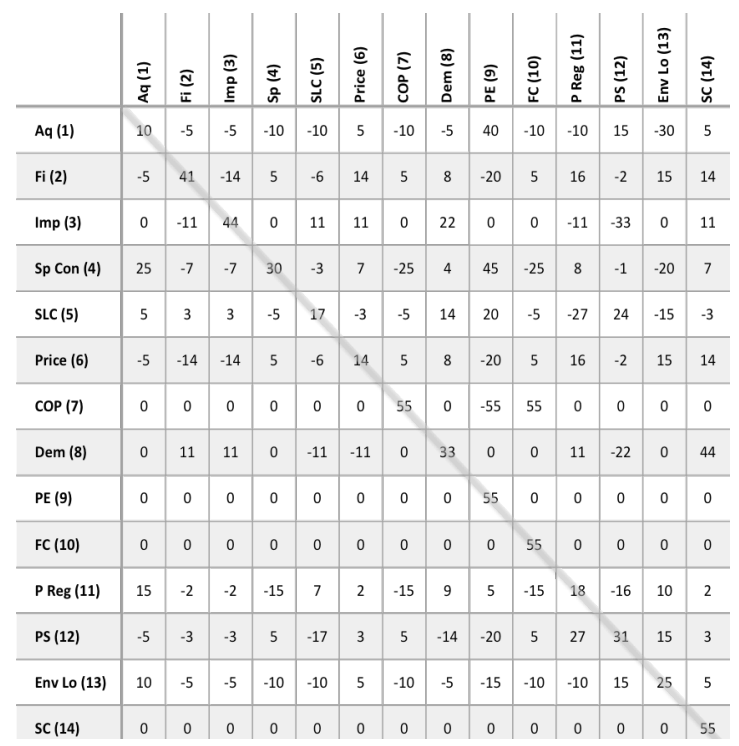


Model

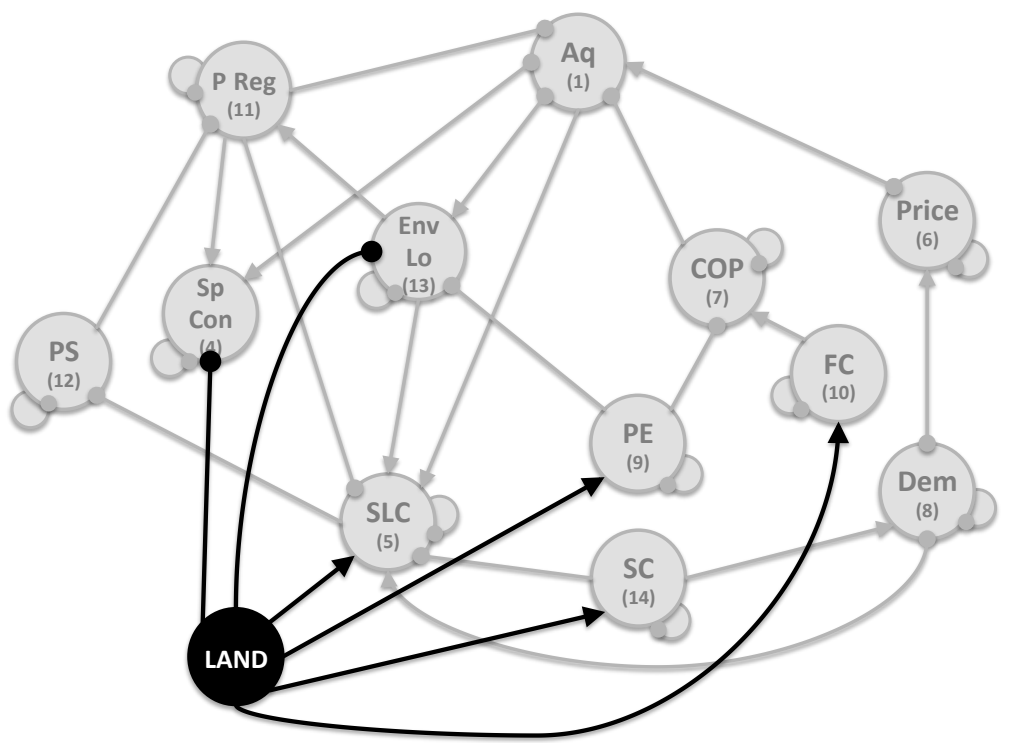

Perturbations

$\begin{array}{cc}\text { Sp Con (4) } & - \text { Ve } \\ \text { SLC (5) } & + \text { Ve } \\ \text { PE (9) } & + \text { Ve } \\ \text { FC (10) } & + \text { Ve } \\ \text { Env Lo (13) } & - \text { Ve } \\ \text { SC (14) } & + \text { Ve }\end{array}$

Community Matrix

\begin{tabular}{|c|c|c|c|c|c|c|c|c|c|c|c|c|c|}
\hline & $\begin{array}{l}\Xi \\
\square \\
\end{array}$ & $\begin{array}{l}\text { త } \\
\text { o } \\
\text { U } \\
\text { in }\end{array}$ & $\frac{\sqrt[n]{u}}{\vec{u}}$ & $\begin{array}{l}\widehat{Q} \\
0 \\
\frac{U}{2} \\
0\end{array}$ & $\begin{array}{l}\bar{E} \\
0 \\
0 \\
0\end{array}$ & $\frac{\widehat{D}}{\varepsilon}$ & $\underset{\frac{\omega}{\alpha}}{\widehat{\sigma}}$ & 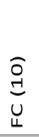 & $\begin{array}{l}\underset{J}{J} \\
\underset{d 0}{0} \\
\alpha \\
\alpha \\
0\end{array}$ & \begin{tabular}{l}
$\bar{N}$ \\
\multirow{J}{n}{} \\
$\tilde{n}$
\end{tabular} & $\begin{array}{l}\widehat{m} \\
\vec{d} \\
0 \\
\vec{J} \\
\vec{w}\end{array}$ & $\begin{array}{l}\underset{J}{J} \\
\underset{U}{J}\end{array}$ & $\begin{array}{l}5 \\
\vdots \\
0 \\
\frac{t}{n} \\
\frac{1}{8}\end{array}$ \\
\hline $\mathrm{Aq}(1)$ & 0 & -1 & 0 & 1 & -1 & 0 & 0 & 0 & -1 & 0 & -1 & 0 & 0 \\
\hline Sp Con (4) & 1 & -1 & 0 & 0 & 0 & 0 & 0 & 0 & 1 & 0 & 0 & 0 & -1 \\
\hline $\operatorname{SLC}(5)$ & 1 & 0 & -1 & 0 & 0 & 1 & 0 & 0 & -1 & 0 & 1 & -1 & 1 \\
\hline Price (6) & -1 & 0 & 0 & -1 & 0 & 1 & 0 & 0 & 0 & 0 & 0 & 0 & 0 \\
\hline $\operatorname{COP}(7)$ & 0 & 0 & 0 & 0 & -1 & 0 & -1 & 1 & 0 & 0 & 0 & 0 & 0 \\
\hline $\operatorname{Dem}(8)$ & 0 & 0 & -1 & -1 & 0 & -1 & 0 & 0 & 0 & 0 & 0 & 1 & 0 \\
\hline $\operatorname{PE}(9)$ & 0 & 0 & 0 & 0 & 0 & 0 & -1 & 0 & 0 & 0 & 0 & 0 & 1 \\
\hline $\mathrm{FC}(10)$ & 0 & 0 & 0 & 0 & 0 & 0 & 0 & -1 & 0 & 0 & 0 & 0 & 1 \\
\hline P Reg (11) & 0 & 0 & 0 & 0 & 0 & 0 & 0 & 0 & -1 & -1 & 0 & 0 & 0 \\
\hline PS (12) & 0 & 0 & -1 & 0 & 0 & 0 & 0 & 0 & 0 & -1 & 0 & 0 & 0 \\
\hline Env Lo (13) & 1 & 0 & 0 & 0 & 0 & 0 & -1 & 0 & 0 & 0 & -1 & 0 & -1 \\
\hline SC (14) & 0 & 0 & 0 & 0 & 0 & 0 & 0 & 0 & 0 & 0 & 0 & -1 & 1 \\
\hline RAS Pert VI & 0 & 0 & 0 & 0 & 0 & 0 & 0 & 0 & 0 & 0 & 0 & 0 & -1 \\
\hline
\end{tabular}

Adjoint Matrix

\begin{tabular}{|c|c|c|c|c|c|c|c|c|c|c|c|c|c|}
\hline & 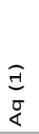 & $\begin{array}{l}\text { वे } \\
\text { c } \\
0 \\
\text { o } \\
\text { in }\end{array}$ & $\begin{array}{l}\hat{n} \\
u \\
\vec{n}\end{array}$ & $\begin{array}{l}\hat{Q} \\
\underline{u} \\
\frac{u}{2} \\
0\end{array}$ & $\begin{array}{l}\bar{Z} \\
\bar{o} \\
\bar{U}\end{array}$ & $\begin{array}{l}\widehat{D} \\
\overline{0} \\
0\end{array}$ & $\underbrace{\hat{\sigma}}_{\frac{\omega}{a}}$ & 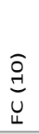 & $\begin{array}{l}\hat{\exists} \\
\underset{d}{0} \\
0 \\
\alpha \\
0 \\
0\end{array}$ & 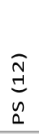 & 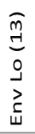 & $\begin{array}{l}\underset{J}{J} \\
\underset{u}{U}\end{array}$ & 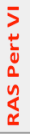 \\
\hline $\mathrm{Aq}(1)$ & 10 & -10 & -10 & 5 & -10 & -5 & 40 & -10 & -10 & 15 & -30 & 5 & 35 \\
\hline Sp Con (4) & 25 & 30 & -3 & 7 & -25 & 4 & 45 & -25 & 8 & -1 & -20 & 7 & 7 \\
\hline $\operatorname{SLC}(5)$ & 5 & -5 & 17 & -3 & -5 & 14 & 20 & -5 & -27 & 24 & -15 & -3 & 27 \\
\hline Price (6) & -5 & 5 & -6 & 14 & 5 & 8 & -20 & 5 & 16 & -2 & 15 & 14 & -16 \\
\hline $\operatorname{COP}(7)$ & 0 & 0 & 0 & 0 & 55 & 0 & -55 & 55 & 0 & 0 & 0 & 0 & 0 \\
\hline $\operatorname{Dem}(8)$ & 0 & 0 & -11 & -11 & 0 & 33 & 0 & 0 & 11 & -22 & 0 & 44 & 19 \\
\hline PE (9) & 0 & 0 & 0 & 0 & 0 & 0 & 55 & 0 & 0 & 0 & 0 & 0 & 30 \\
\hline $\mathrm{FC}(10)$ & 0 & 0 & 0 & 0 & 0 & 0 & 0 & 55 & 0 & 0 & 0 & 0 & 30 \\
\hline P Reg (11) & 15 & -15 & 7 & 2 & -15 & 9 & 5 & -15 & 18 & -16 & 10 & 2 & 2 \\
\hline $\operatorname{PS}(12)$ & -5 & 5 & -17 & 3 & 5 & -14 & -20 & 5 & 27 & 31 & 15 & 3 & -27 \\
\hline Env Lo (13) & 10 & -10 & -10 & 5 & -10 & -5 & -15 & -10 & -10 & 15 & 25 & 5 & -25 \\
\hline SC (14) & 0 & 0 & 0 & 0 & 0 & 0 & 0 & 0 & 0 & 0 & 0 & 55 & 30 \\
\hline RAS Pert VI & 0 & 0 & 0 & 0 & 0 & 0 & 0 & 0 & 0 & 0 & 0 & 0 & 20 \\
\hline
\end{tabular}

